OPEN ACCESS

Edited by:

Mauricio Antonio Retamal, Universidad del Desarrollo, Chile

Reviewed by:

John Cuppoletti,

University of Cincinnati, USA

Luis A. Pardo,

Max Planck Society, Germany

*Correspondence:

Francisco J. Barrantes rtfjb1@gmail.com

Specialty section:

This article was submitted to Membrane Physiology and Membrane Biophysics,

a section of the journa

Frontiers in Physiology

Received: 06 September 2016 Accepted: 09 November 2016 Published: 28 November 2016

Citation: Antollini SS and Barrantes FJ (2016) Fatty Acid Regulation of Voltage- and Ligand-Gated lon Channel Function.

Front. Physiol. 7:573.

doi: 10.3389/fphys.2016.00573

\section{Fatty Acid Regulation of Voltage- and Ligand-Gated Ion Channel Function}

\author{
Silvia S. Antollini ${ }^{1,2}$ and Francisco J. Barrantes ${ }^{3 *}$ \\ ${ }^{1}$ Instituto de Investigaciones Bioquímicas de Bahía Blanca (CONICET-UNS), Bahía Blanca, Argentina, ${ }^{2}$ Departamento de \\ Biología, Bioquímica y Farmacia, Universidad Nacional del Sur, Bahía Blanca, Argentina, ${ }^{3}$ Laboratory of Molecular \\ Neurobiology, BIOMED UCA-CONICET, Buenos Aires, Argentina
}

Free fatty acids (FFA) are essential components of the cell, where they play a key role in lipid and carbohydrate metabolism, and most particularly in cell membranes, where they are central actors in shaping the physicochemical properties of the lipid bilayer and the cellular adaptation to the environment. FFA are continuously being produced and degraded, and a feedback regulatory function has been attributed to their turnover. The massive increase observed under some pathological conditions, especially in brain, has been interpreted as a protective mechanism possibly operative on ion channels, which in some cases is of stimulatory nature and in other cases inhibitory. Here we discuss the correlation between the structure of FFA and their ability to modulate protein function, evaluating the influence of saturation/unsaturation, number of double bonds, and cis vs. trans isomerism. We further focus on the mechanisms of FFA modulation operating on voltage-gated and ligand-gated ion channel function, contrasting the still conflicting evidence on direct vs. indirect mechanisms of action.

Keywords: ion channels, cell-surface receptors, ligand-gated channel, fatty acids, PUFA, FFA, VLCFA

Free fatty acids (FFA) are customarily studied in relation to the physical adaptation of cells to their environment, the normal metabolism of lipids and carbohydrates (lipogenesis, lipolysis, esterification, oxidation, glycolysis, fatty acid uptake) and disease conditions, such as obesity, atherogenic dyslipidemias, type 2 diabetes, or insulin resistance (Boden, 2008). This broad palette is largely associated with the physiology and physiopathology of FFA resulting from the lipolytic breakdown of stored tissular triglycerides. Other diseases involving pathological affectation of fatty acids, albeit rare, include X-linked adrenoleukodystrophy, a progressive neurodegenerative disorder caused by the loss-of-function mutation in the ATP-binding cassette transporter subfamily $\mathrm{D}$ member 1 gene. The transporter mediates the transport of saturated very long-chain fatty acids (VLCFA), and the disease displays an abnormal accumulation of VLCFA (Mosser et al., 1993). In addition to these systemic and more general effects of FFA, the activity of many membrane proteins is modulated by the lipid composition of the membranes in which they are embedded and the physicochemical properties of the FFA produced locally are increasingly gaining attention in this regulatory role. FFA are normal constituents of biological membranes that are continuously being produced and catabolized in living cells. No consensus view has emerged to date to account for the mechanisms by which this type of lipids modulate membrane proteins (Ordway et al., 1991; Petrou et al., 1995); it is highly likely that they will turn out to be multifactorial in nature. Under certain stress conditions and most particularly in brain, the amount of endogenous FFA can

Abbreviations: FFA, free fatty acids; nAChR, nicotinic acetylcholine receptor; PUFA, polyunsaturated fatty acids; TM, transmembrane; VLCFA, very long-chain fatty acids. 
increase dramatically, a phenomenon that has been interpreted as fulfilling a neuroprotective function (see Lauritzen et al., 2000; Blondeau et al., 2002; Buckler and Honore, 2005). Events like ischemia, hypoxia and kainate-induced epilepsy cause a decrease in the intracellular $\mathrm{pH}$, augmented intracellular FFA concentration and an increase in the cytoplasmic $\mathrm{Ca}^{2+}$ concentration, leading to the activation of phospholipases. Lauritzen et al. (2000) showed that the PUFA linolenic acid (n-3 PUFA) prevents neuronal death in an animal model of transient global ischemia even when administered as long as 30 min after the insult. Linolenic acid also protected animals treated with kainate against seizures and hippocampal lesions. The augmentation of both the $\mathrm{pH}$ and cytosolic FFA concentrations causes hyperpolarization of the cell membrane and reduces the $\mathrm{Ca}^{2+}$ influx, thus deterring excitatory glutamatergic transmission and preventing neuronal death, pointing to the possible role of FFA as neuroprotective agents and anti-epileptic compounds (Lauritzen et al., 2000). In addition, dysfunction in fatty acid metabolism is implicated in disease conditions, such as cardiovascular disease, metabolic syndrome, type 2 diabetes, obesity, hypertension and proimflammatory conditions, as well as in several neurological diseases related to the alteration of insulin equilibrium in brain, as observed in Parkinson's disease, Alzheimer's disease and some forms of the schizophrenic spectrum disorders (Virmani et al., 2015).

It is well documented that FFA can directly or indirectly affect the activity of a variety of ion channels. The former involves the interaction between FFA and the ion channel protein or an associated site within the membrane without intervening factors or intermediaries; indirect effects involve the prior transformation of FFA to biologically active metabolites (Ordway et al., 1991), usually through signaling cascades. FFA effects on ion channels depend on their chemical structure: some ion channels are affected by both saturated and unsaturated fatty acids whereas others are only affected by unsaturated fatty acids (Ordway et al., 1991; Sumida et al., 1993; Meves, 1994). Similarly, cis and trans FFA isomers have been postulated to exert effects on some ion channels whereas only the cis configuration has been identified in other cases (Ordway et al., 1991; Sumida et al., 1993; Meves, 1994). An example of this occurs in the hypertriglyceridemia associated with acute pancreatitis. Hydrolysis of triglycerides by pancreatic lipase in acinar cells releases large quantities of FFA, which trigger an increase in cytosolic $\mathrm{Ca}^{2+}$ concentration, an effect that depends on the unsaturated/saturated FFA ratio. High concentrations of unsaturated fatty acids lead to an elevation of cytosolic $\mathrm{Ca}^{2+}$ and induce the expression of distinct isoforms of the enzyme phosphokinase C (PKC), the activity of which directly depends on the degree of FFA unsaturation (Chang et al., 2015).

Early fluorescence measurements undertaken by Karnovsky (1979) to study possible membrane alterations induced by FFA led to the classification of FFA into two groups: group A, containing cis-unsaturated FFA with a kink in the molecule (such as oleic and palmitoleic acids), and group B, comprising saturated and trans-unsaturated fatty acids with a linear structure (such as stearic and elaidic acids). This structural difference has important biophysical implications. Group A fatty acids disorder the membrane's interior and order the more shallow head group region, whereas members of group B do not alter the bilayer core but order the head group region. Such structure-dependent perturbations can lead to conformational changes in membraneembedded proteins, a fact reflected in various communications reporting differences in biological activity for group A and group B FFA (Casabiell et al., 1991; Pérez et al., 1997, 2003).

Despite the plethora of studies concerning the relationship between FFA and proteins-in particular ionic channels and receptors- it has not been possible to find a common mechanism of action: whereas in some cases FFA stimulate some functional property of the protein in question, in other cases they act as inhibitors. Furthermore, in some cases the structure of the FFA is determinant (saturated vs. unsaturated; one or two vs. more double bonds; cis double bonds vs. trans double bonds) whereas in other cases the detailed chemical structure does not appear to play a key role; in some cases the FFA acts directly on the target protein whereas in others the FFA does so by activating an intracellular cascade that eventually results in protein modulation. In the following sections, examples of FFA modulation of distinct ion channels will be discussed with special emphasis on the voltage-gated ion channels and the nicotinic acetylcholine receptor ( $\mathrm{AAChR}$ ), paradigm of the rapid ligand-gated ion channels. From the point of view of the messenger, in this review we restrict ourselves to the analysis of the modulatory effects caused exclusively by FFA, without dwelling on the changes in the membrane microenvironment produced by the retailoring of the fatty acyl chain composition of either phospholipid or cholesterol ester molecular species. From the point of view of the target molecule, we also circumscribe ourselves to the ion channels, leaving aside e.g., the interesting field of G-protein-coupled receptors (GPCRs) acting as sensors of metabolic state, and activated by short-chain fatty acids, i.e., the so-called FFA receptors (Hudson et al., 2013).

\section{FFA EFFECTS ON VOLTAGE-GATED ION CHANNELS}

\section{Potassium $\left(\mathrm{K}^{+}\right)$Channels}

$\mathrm{K}^{+}$channels comprise a large superfamily of integral membrane proteins displaying diverse functions in essentially all organs of vertebrate and invertebrate organisms. Structurally, they possess several transmembrane (TM) helices spanning the lipid bilayer. Based on the combination of their structural and functional characteristics, the $\mathrm{K}^{+}$channel superfamily can be divided into three main families: voltage-gated (Kv, 6 TMs), inwardly rectifying (Kir, $2 \mathrm{TMs}$ ), and tandem pore domain (K2P, 4 TMs) channels (Kuang et al., 2015). The modulation of these channels by FFA has been documented in numerous instances.

$K v$ channels are the third-largest class of signal transduction proteins, second only to $G$ protein-coupled receptors (GPCRs) and protein kinases (Yu and Catterall, 2004). The pioneer work of Villarroel and Schwarz (1996) studied the effect of arachidonic acid (AA) over 12 different $\mathrm{K}^{+}$channels expressed in Xenopus laevis oocytes. Different effects (inhibition or enhancement of the channel current) were observed for each channel; the greatest 
effect was observed in the rat K4.2 channel. The current reduction in the presence of AA was near $68 \%$, with an almost total current recovery upon AA removal by washout or bovine serum albumin addition. A similar effect was observed in the presence of 5,8,11,14-eicosatetraynoic acid (ETYA), a nonhydrolizable AA analog. The authors discarded an effect mediated by (1) the metabolic processing of AA by cyclooxygenase, lipooxygenase or epoxygenase pathways, (2) an increment in intracellular $\mathrm{Ca}^{2+}$, or (3) activation of a PKC. By testing different FFA, they also discarded the possibility that the effect of AA on the Kv4.2 channel was mediated by an indirect mechanism related to alteration of the membrane fluidity. The authors postulated a direct mechanism mediated by the specific interaction of AA with the channel; although they could not find the binding site for AA, they suggested that the S4-S5 loop is indirectly involved. In the same work (Villarroel and Schwarz, 1996), the authors described a potentiation effect of AA on the Shaker Kv channel, the prototypic member of the family, with perturbations of the activation and inactivation kinetics, an effect that was not reproduced with ETYA. Later works continue the study of this effect. Modulation by FFA of the Shaker Kv channel shifts the voltage dependence of activation via an electrostatic mechanism that ends in channel activation (Börjesson et al., 2008, 2010; Xu et al., 2008). The observed effect was similar for six different polyunsaturated fatty acids (PUFA), whereas monounsaturated and saturated fatty acids produced no effect (Börjesson et al., 2008). The charge of the PUFA head group determines the direction of the effect, which has been referred to as the "lipoelectric mechanism" (Börjesson et al., 2008, 2010). FFA can also induce channel opening by affecting one or several of the steps/molecular rearrangements leading to channel opening. Studying point-mutated Shaker channels covering the lipophilic surfaces of the extracellular helices of S3, S4, S5, and S6 segments, Börjesson and Elinder (2011) concluded that residues in the voltage sensor domain are important for PUFA acting on the channel's voltage dependence, with high-impact residues clustered in a small region of the lipid-facing S3-S4 bend, where these authors tentatively assign the location of the PUFA site of action. Börjesson and Elinder (2011) further demonstrated that PUFA cause very different effects on different ion channels depending on the presence of charges at specific positions. A recent in silico study employing atomistic molecular dynamics simulations identified a similar potential PUFA site in the open channel state of Shaker $\mathrm{K}_{\mathrm{V}}$, located at the lipidfacing side of a pocket connecting the extracellular linker between S3 and S4 helices (Yazdi et al., 2016). This study also provided an explanation for the activation caused by FFA: the selective stabilization of the open state of the Kv channel as PUFA established fewer interactions with the protein in the closed state. Interestingly, Yazdi et al. (2016) point out that PUFA induce channel opening by modulating voltage-sensitivity, thus opening a potential therapeutic avenue for the use of ketogenic diets in refractory epilepsy.

Background $\mathrm{K}^{+}$channels (4 TMs and 2 pore domain, 2P) play a key role in setting the neuronal membrane potential, in tuning the duration of the action potential and in modulating the membrane input resistance. Kim (2003) reviewed the main characteristics of the modulation of two-pore domain $\mathrm{K}^{+}$channels by FFA (TREK-1, TREK-2, and TRAAK). These channels, activated by GPCRs, stretch, $\mathrm{pH}$, and PUFA, are broadly expressed in the nervous system where they control neuronal excitability (Lee et al., 2011; Liu et al., 2014; Blin et al., 2016). The effect of PUFA on TREK channels has profound physiological implications, since TREK-1 was shown to mediate the neuroprotection induced by PUFA (Lauritzen et al., 2000; Heurteaux et al., 2004; Noël et al., 2011; Liu et al., 2014). There are certain structural features that FFA must necessarily satisfy to activate these $\mathrm{K}^{+}$channels: the length of the carbonyl group, the unsaturation (saturated FFA are not effective) and the presence of the negatively charged carboxyl group (Patel et al., 2001; Kim, 2003; Noël et al., 2011). It has been demonstrated that the effect of PUFA on fatty acid-sensitive two-pore domain $\mathrm{K}^{+}$channels does not require metabolic conversion of fatty acids into other bioactive molecules nor cytosolic messengers, enzymes or $\mathrm{Ca}^{++}$ (Horimoto et al., 1997; Maingret et al., 1999; Casavant et al., 2000; Lee et al., 2011). Thus, the effect of FFA could result from direct interaction with the channel protein, via partitioning into the lipid bilayer (e.g., causing changes in membrane fluidity), and/or involving membrane-delimited signal transduction mechanisms (Casavant et al., 2000). Compounds that mimic the effect of AA on membrane properties did not reproduce the effect of FFA on $\mathrm{K}^{+}$channels (Patel et al., 2001). TREK and TRAAK are, however, mechano-gated channels that preferentially open by negative mechanical pressure (i.e., convex membrane curvature); it is thus possible that FFA are involved or even induce membrane alterations that lead to changes in membrane curvature (Patel et al., 2001). It has been reported that the cytoplasmic Cterminal region of near 30 amino acids located close to the 4 th TM segment of the TREK-1 or TREK- $2 \mathrm{~K}^{+}$channels confers sensitivity to unsaturated FFA (Patel et al., 1998; Kim, 2003; Lee et al., 2011). Furthermore, using deletion analysis it has been reported that not only the C-terminal group but also the extracellular loop between the 1st TM domain and the 1st pore domain may be important for this effect (Patel et al., 2001).

The large-conductance $\mathrm{Ca}^{++}$-activated $\mathrm{K}^{+}$channels (Slo1 BK channels), a very diverse group of channels resulting from alternative splicing in the CNS, are involved in the regulation of multiple physiological processes (Brenner et al., 2000). Similarly, a large number of cellular signaling molecules, including FFA, are known to modulate the function of Slo1 BK channels. For instance, BK channels are activated by FFA in $\mathrm{GH}_{3}$ cells (Denson et al., 2000), whereas a clonal line derived from $\mathrm{GH}_{3}$ $\left(\mathrm{GH}_{4} \mathrm{C}_{1}\right)$ does not respond to $\mathrm{AA}$, suggesting an alternative BK splice variant in these cells (Duerson et al., 1996). In $\mathrm{GH}_{3}$, BK channel activation by FFA requires a FA with at least one double bond, and a significant correlation was described between the degree of cis-unsaturation and the extent of channel activation (Denson et al., 2000). No significant correlation between changes in membrane fluidity and degree of activation was observed, and no effect of FFA metabolites was detected, leading to the conclusion that cis-unsaturated FFA interact directly with the channel protein proper. It was suggested that binding of the FFA to the $\mathrm{Ca}^{2+}$ binding site (a domain near the inner surface of the membrane in the cytosolic tail of the 
channel) could be responsible for changes of the channel protein conformation and hence changes in $\mathrm{Ca}^{2+}$ affinity, resulting in a conformation with a lower energy state (Denson et al., 2000). Further structural features of FFA required to increase BK channel activity have been defined: FFA must have a negatively charged head group and a sufficiently long $(C>8)$ carbon chain (Clarke et al., 2002). These authors showed that channel modulation is unlikely to be due to an alteration of the membrane electric field or the attraction of local counterions to the channel, concluding that FFA modulation of $\mathrm{BK}(\mathrm{Ca})$ channels could occur by direct interaction with either the channel protein or with some other channel-associated component. Sun et al. (2007) postulated a novel mechanism of $\beta$-subunit-dependent modulation of BK channels by AA. Further studies also suggested that docosahexanoic acid (DHA) directly activates the Slo1 channel complex with the auxiliary subunit $\beta 1$ by destabilizing the closed conformation of the ion conduction gate (Hoshi et al., 2013a). Electrophysiological measurements showed that a single residue near the cytoplasmic end of S6 plays a critical role in the DHA activation of human Slo1 as no effect was observed on Drosophila melanogaster Slo1 channels, which normally do not contain DHA in the body (Hoshi et al., 2013b). Mutation of Y318, located probably at the cytoplasmic end of S6 in hSlo1 to Y318S, as found in dSlo1, cancels the effect of DHA on hSlo1 (Hoshi et al., 2013b).

One of the initial events in $\beta$-cells glucose stimulus-insulin secretion coupling is the closure of the ATP-sensitive $\mathrm{K}^{+}$channel. It has been demonstrated that an increment in the concentration of FFA results in decreased insulin secretion (Corkey et al., 1989). The effect of FFA was shown to be dual: the initial products of phospholipase A2 digestion, or exogenous FFA, resulted in the reduction of ATP-sensitive $\mathrm{K}^{+}$channel activity, whereas i) a long-term activation of these channels by $\mathrm{AA}$, and ii) the reversal of this effect by AA metabolites via the cyclooxygenase pathway are also observed, possibly responding to a counterregulatory mechanism (Eddlestone, 1995). Overnight incubation of clonal $\beta$-cells with palmitic acid induced a $50 \%$ decrease in the ability of glucose to stimulate insulin secretion and increased the pool of long-chain CoA (LC-CoA, the metabolically active form of FFA) (Larsson et al., 1996). Oleoyl-CoA increased the mean current 5 -fold. Furthermore, the ability of LC-CoA to increase $\mathrm{K}^{+}$conductance appears to be specific for the $\mathrm{K}_{\mathrm{ATP}}$ channel (and not for the big conductance $\mathrm{K}^{+}$channel, $\mathrm{K}_{\mathrm{BK}}$, which is voltage and $\mathrm{Ca}^{2+}$-dependent, nor for 8-pS $\mathrm{K}^{+}$channel). The stimulatory effect of the LC-CoA was dependent on both the acyl group (saturated or unsaturated chains with 14 to 18 carbons) and the CoA component. The accumulation of LC-CoA, possibly as a consequence of high glucose exposure (which inhibits fatty acid oxidation and elevates cytosolic LCCoA levels), could be causally related to a loss of responsiveness to glucose. In tissue culture or non-insulin-dependent diabetes mellitus, long-term exposure to FFA impairs glucose-induced insulin by preventing the closure or promoting the opening of $\mathrm{K}_{\mathrm{ATP}}$ channels (Larsson et al., 1996). LC-CoA esters with a chain length exceeding 12 carbons were also observed to be potent activators of the $\mathrm{K}_{\mathrm{ATP}}$ channel in human pancreatic beta cells (Bränström et al., 2004). Previously it was demonstrated that fatty acid activation of ATP-sensitive $\mathrm{K}^{+}$channels was most likely due to the participation of AA (and other cis-unsaturated fatty acid)-activated protein kinase $C$ (PKC) isoenzymes and not by metabolites of AA via the cyclooxygenase or the lipoxygenase pathways (Müller et al., 1992). Similarly, a direct connection between AA and PKC activation was experimentally tested, explaining the mitogenic potential of AA (4-fold increase in DNA synthesis) in rat brown preadipocytes (Garcia et al., 2012). AA was in fact shown to activate PKC in various tissues, albeit by different mechanisms of action (Sekiguchi et al., 1987; Shinomura et al., 1991; Chen and Murakami, 1992; Blobe et al., 1995; Nishizuka, 1995; Nowicki et al., 1997; Leu et al., 2010). AA inhibition of $\mathrm{Na}^{+}-\mathrm{K}^{+}$-ATPase in sheep pulmonary artery was postulated to be mediated mainly by 20-HETE, the major metabolite of cytochrome P-450-arachidonic acid $\omega$-hydroxylase pathway, through the activation of PKC (Singh et al., 2012). A similar mechanism was postulated in rat proximal convoluted tubules (Li et al., 2000). Nowicki et al. (1997) postulated that this inhibition was mediated by PKC-phosphorylation of Ser23 on the $\mathrm{Na}^{+}, \mathrm{K}^{+}$-ATPase $\alpha$ subunit. Another study suggested that 20 HETE can lead to PKC-dependent phosphorylation of Ser23 in $\mathrm{Na}^{+}-\mathrm{K}^{+}$-ATPase and of Ser896 in NMDA receptor NR1subunits at the putamen of piglets (Yang et al., 2012). A further study demonstrated that AA improved prostate cancer cell survival through 5-lipoxygenase (5-LOX) metabolites, a process which involved downstream PKCE activity (Sarveswaran et al., 2011). These authors further showed that treatment of prostate cancer cells with MK591, a 5-LOX inhibitor, or 5-LOX shRNA not only decreased $\mathrm{PKC} \varepsilon$ expression but also diminished membrane localization of $\mathrm{PKC} \varepsilon$, inducing apoptosis. $\mathrm{PKC} \varepsilon$ may thus be a mediator of survival signals downstream of 5-LOX metabolites (Sarveswaran et al., 2011).

Fatty acids act as substrates for acyl-coenzyme A (acylCoA) molecules by several synthases. These activated fatty acids can be short-chain (acetyl-CoA), medium-chain (e.g., octanoyl-CoA) or long-chain acyl-CoAs, such as palmitoylCoA. The effect of FFA and acyl-CoA esters on a highly active plant mitochondrial ATP-sensitive $\mathrm{K}^{+}$channel (PmitoKATP) was studied in mitochondria isolated from durum wheat (Triticum durum Desf.) (Laus et al., 2011). Acyl-CoAs, linoleate and other FFA (laurate, palmitate, stearate, palmitoleate, oleate, arachidonate, and the non-physiological 1-undecanesulphonate and 5-phenylvalerate) directly activate PmitoKATP, but not through the Plant Uncoupling Protein (PUCP). The same activation effect was found to be widespread in mitochondria from different plant species and organs. Since PmitoKATP may act against environmental/oxidative stress (Atkin and Macherel, 2009), FFA activation in plants has been proposed to represent a physiological anti-stress mechanism: under hyperosmotic $(\mathrm{NaCl}$ or mannitol) stress conditions, FFA increase and may activate PmitoKATP strongly (Laus et al., 2011).

In rat atrial myocytes, perfusion of the cytoplasmic face of the membrane with unsaturated FFA $(10-50 \mu \mathrm{M})$ such as AA, linoleic, and eicosatrienoic acids was reported to inhibit the ATPsensitive $\mathrm{K}^{+}$channel almost completely; lysophospholipids also markedly inhibited channel openings. In contrast, AA activated the ATP-insensitive $\mathrm{K}^{+}$channel with an outwardly rectifying 
property. Since the FFA levels rise after long periods of ischemia, the authors speculated that the ATP-insensitive $\mathrm{K}^{+}$channels contribute to a late phase of extracellular $\mathrm{K}^{+}$accumulation (Kim and Duff, 1990).

$\mathrm{Ca}^{++}$-dependent basolateral membrane $\mathrm{K}^{+}$channel $\left(\mathrm{K}_{\mathrm{Ca}}\right)$ activation in intestinal cells induces membrane hyperpolarization and $\mathrm{Cl}^{-}$secretory current. It was demonstrated that $\mathrm{AA}$ is a second messenger in this pathway: AA levels increase via $\mathrm{Ca}^{2+}$. dependent agonists through different pathways (PLA2, DAG, or DAG lipase) and induce a temporal modulation of $\mathrm{Cl}^{-}$secretion. The inhibition of $\mathrm{K}_{\mathrm{Ca}}$ can occur both through the extracellular or intracellular side of the channel and does not depend on the generation of either cyclooxygenase or lipooxygenase metabolites (Devor and Frizzell, 1998). This $\mathrm{K}_{\mathrm{Ca}}$ inhibition was not specific for AA, as other FFA showed similar effects albeit to a lesser extent. A FFA effect caused by membrane fluidity changes was discarded as a plausible hypothesis, because different FFA act in a similar way on $\mathrm{K}_{\mathrm{Ca}}$ but induce deviations from the optimal membrane fluidity in either direction (Devor and Frizzell, 1998). Hamilton et al. (2003) concluded that AA exerts a direct effect on $\mathrm{K}_{\mathrm{Ca}}$ channel (identified as hIK1/hSK4) and described a secondmessenger binding site for AA and other FFA. The AA sensitivity of hIK1 lies within the S5 pore and the S6 region, two amino acids $\left(\mathrm{Thr}^{250}\right.$ and $\mathrm{Val}^{275}$ ) being crucial for this modulation. The side chains of both amino acids extend into the hIK1pore, suggesting that AA causes a direct pore block.

A medically important area of FFA modulation of ion channels is without doubt the mechanism underlying the antior pro-arrhythmic effects exerted on cardiac ion channels. PUFA were shown to reduce membrane electrical excitability of neonatal cardiac myocytes and provide an electrophysiological basis for the antiarrhythmic effects of these fatty acids (Kang et al., 1995). Research in this field has developed rapidly and insights into the action of FFA on cardiac myocytes have exploded. An example is the multiple and complex series of effects observed after $n$-3 supplementation, summarized by Moreno et al. (2012): " $n-3$ PUFA inhibit the fast sodium current $\left(I_{\mathrm{Na}}\right)$, ultrafast activating delayed outward potassium current $\left(I_{\text {Kur }}\right)$, transient outward potassium current $\left(I_{\text {to }}\right)$, rapidly activating delayed rectifying outward potassium current $\left(I_{\mathrm{Kr}}\right)$, L-type calcium inward current $\left(I_{\mathrm{Ca}}\right)$, and $\mathrm{NaC}-\mathrm{Ca} 2 \mathrm{C}$ exchange current $\left(I_{\mathrm{NCX}}\right)$, and enhanced slowly activating delayed rectifying outward potassium current $\left(I_{\mathrm{Ks}}\right)$ and inward rectifying potassium current $\left(I_{\mathrm{K} 1}\right)$." It is still not clear, however, which is the mechanism operative in n-3 FFA modulation of ion channels: is it a direct or an indirect effect? The prevalent opinion is to consider a direct interaction of FFA with the ion channel protein proper (Moreno et al., 2012 and references therein). Guizy et al. (2005) reported a blocking effect of both AA and DHA on human ether-a-go-gorelated gene (HERG) channels, whose activation determines the duration of the action potential. This effect, which was found to depend on time, voltage and channel conformational state, was compatible with an open-channel block mechanism. The fact that ETYA caused a similar blockage effect suggests that these PUFA act through a direct mechanism and not through AA metabolism. Clearly, this mechanism requires the channel to be in an open state, but changes in the channel gating parameters suggest that these FFA also interact with the closed state. The inhibition action of these FFA on HERG channels can help to further explain the reported antiarrhythmic effects of AA and/or DHA (Guizy et al., 2005). Open-channel blockage by polyunsaturated FFA, apparently by binding of the FFA to an external site in the channel, was also reported for the major voltage-dependent $\mathrm{K}^{+}$ channel (Kv1.5) cloned from cardiac cells (Honoré et al., 1994; Guizy et al., 2008). In contrast to this effect, Gavrilova-Ruch et al. (2007) reported that AA activated human ether à go-go (hEAG) potassium channels expressed in $\mathrm{CHO}$ cells, an effect totally reversed upon washing with BSA. The potentiation effect was directly dependent on the number of cis-double bonds in the FFA, and probably involved a direct mechanism of action, as ETYA also potentiated hEAG currents, presumably acting through the outer membrane leaflet. The fact that FFA activate hEAG channels whereas they inactivate HERG channels may be due to structural differences in the pore mouth which, in the case of hEAG channels, would prevent the access of AA to the permeation pathway. These channels are normally expressed in neuronal tissue but also in various tumoral tissues, pointing to a possible oncogenic role; the activating effect of $\mathrm{AA}$ on EAG channels has therefore been related to an enhanced tumor proliferative rate (Gavrilova-Ruch et al., 2007).

\section{Anion Channels}

Anion channels, $\mathrm{ClC}-2 \mathrm{Cl}^{-}$channels in particular, are widely distributed in epithelial and non-epithelial tissues. One of the potentially lethal, inherited diseases affecting $\mathrm{Cl}^{-}$channels is cystic fibrosis. The disease is caused by mutations in the gene encoding a cAMP-regulated, phosphorylation-gated $\mathrm{Cl}^{-}$ channel, the cystic fibrosis transmembrane conductance regulator (CFTR). CFTR-mediated $\mathrm{Cl}^{-}$and bicarbonate transport drives fluid secretion across epithelial cells. In the gastrointestinal tract, the pathological alteration or loss of CFTR function severely hampers the production of exocrine pancreatic and intestinal secretions, leading to incomplete food digestion and malabsorption. In CF newborns, the defective fluid secretion may lead to a life-threatening obstruction of the distal small intestine, the so-called meconium ileus syndrome. In the pulmonary tract, the CFTR plays a major role in maintaining the airway surface protected by a fluid biofilm. It is therefore not surprising that the respiratory tract is often the target of secondary infections and pneumonia by the combination of CFTR and defective mucosal immunity, Pseudomona aeruginosa being the main pathogen involved. The CFTR is inhibited by several fatty acids in the following order: linoleic $\geq$ arachidonic $\geq$ oleic $>$ elaidic $\geq$ palmitic $\geq$ myristic (Linsdell, 2000). The mechanism of $\overline{A A}$ inhibition has been suggested to result from the electrostatic interaction of the FFA with positively charged amino acids located at the cytoplasmic vestibule of the CFTR channel pore (Zhou and Linsdell, 2007), pointing to a more general inhibitory mechanism of apical membrane $\mathrm{Cl}^{-}$channels by different FFA, which would act from the cytosolic surface thus rejecting the idea that inhibition results from changes in membrane fluidity (Anderson and Welsh, 1990). 
Mutations in the CFTR $\mathrm{Cl}^{-}$channel are associated with severe lung disease in about $5 \%$ of cystic fibrosis patients, a condition that may lead to death. Consequently, a possible therapeutic approach for cystic fibrosis is the potentiation of alternative pathways for $\mathrm{Cl}^{-}$transport in the lung, including the targeting of $\mathrm{ClC}-2 \mathrm{Cl}^{-}$channels in the epithelium of the respiratory tract. These channels were found to be activated by oleic, elaidic and arachidonic acids and by CAMP-dependent PKA, but AA was found to increase the $\mathrm{Cl}^{-}$currents in a PKC-and PKAindependent manner (Tewari et al., 2000). The increment of $\mathrm{Cl}^{-}$currents was FFA dose-dependent, and only observed with unsaturated FFA indistinctly of cis or trans isomerism. The authors postulated that the effect of FFA may be due to direct effects on the channels, probably through mechanisms similar to those underlying the effect of FFA on the TREK-1 channel described above, and not to products of FFA metabolism (Tewari et al., 2000).

\section{Sodium $\left(\mathrm{Na}^{+}\right)$Channels}

Cardiac $\mathrm{Na}^{+}$channels (the major class of ion channels that determines cardiac excitability) are also modulated by FFA, causing a reduction in the electrical excitability and/or automaticity of cardiac myocytes. Here again, it is postulated that the inhibition is dependent on FFA structure (Kang et al., 1995; Xiao et al., 1995), reversible in the presence of BSA, and not mediated by FFA metabolites (Kang and Leaf, 1996; Xiao et al., 1997). The mechanisms by which they exert their action remain uncertain; however, it is postulated that FFA act as non-competitive inhibitors, through a single class of sites, by an allosteric inhibitory mechanism (Kang and Leaf, 1996). These authors postulated a model in which the FFA hydrophobic portion interacts with the hydrophobic TM domains of the channel protein at either the lipid-channel interface or at the space between hydrophobic protein domains; the negatively charged carboxyl group interacts ionically with the positively charged amino acid residues of the channel protein near the surface of the bilayer where the carboxyl group is anchored. Cardiac $\mathrm{Na}^{+}$channels consist of two subunits: the $\alpha$ subunit (the largest one, itself constituting a functional channel) and the $\beta$ subunit (smaller; it interacts functionally with the regulatory segments of the $\mathrm{Na}^{+}$channel) (An et al., 1998). FFA rapidly and strongly suppress voltage-gated $\mathrm{Na}^{+}$currents in cells transfected with only the $\alpha$-subunit of the human cardiac $\mathrm{Na}^{+}$channel and prolong the duration of its inactive state, probably by binding to the inactivated form of the channel (in this state the channel displayed a 43-fold higher affinity for FFA than channels in the resting state) (Xiao et al., 1998). However, not only PUFA but all FFA exerted effects, leading these authors to the conclusion that the characteristic specificity of the effects of PUFA on native $\mathrm{Na}^{+}$currents was lost in the exclusive presence of the $\mathrm{Na}^{+}$ channel $\alpha$ subunit. Xiao et al. (1998) also postulated that the configuration of the $\alpha$-subunit may be more open or uncovered in the absence of other components of the intact voltage-dependent human cardiac $\mathrm{Na}^{+}$channel, thus allowing even those FFA lacking the two or more double bonds to gain access to the site(s) at which PUFA affect conductance in the complete channel. The authors suggested that a short cytoplasmic segment of the transfected channel, linking the III and IV TM segments, was the site of action of FFA (Xiao et al., 1998). Co-expression of the $\beta$-subunit with the $\alpha$-subunit of the human cardiac $\mathrm{Na}^{+}$ channel restores the selective effect of the PUFA, leading to the conclusion that the $\beta$-subunit modifies the FFA blockage of the $\mathrm{Na}^{+}$channel (Xiao et al., 2000). A study with the $\mathrm{hH} 1(\alpha) \mathrm{Na}^{+}$ channel led to the discovery of the importance of Asn 406 in the inhibition of cardiac voltage-gated $\mathrm{Na}^{+}$currents by PUFA (Xiao et al., 2001). Another study using cells transfected with the skeletal muscle sodium channels (SkM1) isoform showed that ion channel modulation by FFA depends on the mode of FFA administration (Wieland et al., 1996). Intracellular AA exposure increased channel currents whereas the $\mathrm{hH} 1$ isoform did not show significant current increases. Thus, the response to FFA must include an isoform-specific element. In contrast, both isoforms were inhibited when unsaturated FFA were applied extracellularly. These results point to the existence of two distinct sites and mechanisms for FFA modulation of sodium channels: a potential extracellular site for extracellular FFA, and an intracellular one that appears to be exclusively for SkM1. The activation effect was observed over $120 \mathrm{~min}$, suggesting that neo-synthesis and trafficking/insertion of new channels to/in the cell membrane could occur during this period, alone or in combination with unmasking of reserve channels already present in the plasmalemma (Wieland et al., 1996). This dual mechanism was also observed in the muscle $r \mathrm{Na}(\mathrm{V}) 1.4$ channel isoform, which appears to depend on the depolarizing potential: AA, but not its metabolites, increased the channel current evoked by a -30 or $-40 \mathrm{mV}$ depolarization of the membrane potential, but significantly decreased it by a depolarization over $-10 \mathrm{mV}$ ( Gu et al., 2009). It was also reported that cis-unsaturated FFA with a double bond at position 9 have a biphasic effect on connexin 46 hemichannels: current activation at low FFA concentration and current inhibition at higher concentrations, the effect being directly proportional to the number of double bonds (Retamar et al., 2011). The authors ruled out the possibility that the biphasic effect was mediated by changes in the biophysical properties of the plasma membrane. They concluded that activation and inhibition current mechanisms involve different sites of action (Retamar et al., 2011).

A different dual mechanism of AA action has been postulated for the modulation of $\delta$-opioid receptor (DOR) function (Sullivan et al., 2015). This modulation involves regulation by cyclooxygenase (COX) and lipoxygenase (LOX) dependent metabolites and activation of PKC. A COX-dependent metabolite of AA induces a responsive state of DOR that is capable of mediating antinociception and inhibition of adenylyl cyclase activity in response to opioid agonists, whereas a novel LOXdependent metabolite of AA produces a loss of responsiveness of the DOR system. Sullivan et al. (2015) further demonstrated that exogenously added and endogenously produced AAs follow different metabolic processes, pointing to the existence of subcellular compartmentation of the enzymes involved. This dual regulation of DOR function may explain the observed variations in the efficacy of opioids in the treatment of pain. Another dual mechanism of FFA is described below for nicotinic acetylcholine receptors. 


\section{FFA EFFECTS ON IONOTROPIC NEUROTRANSMITTER LIGAND-GATED ION CHANNELS}

The regulation of rapid ligand-gated ion channels by fatty acids is illustrated using two paradigmatic cases, the $\gamma$-amino butyric acid receptor and the nicotinic acetylcholine receptor.

\section{$\gamma$-Amino Butyric Acid Receptor (GABA-R)}

Exogenously added unsaturated FFA, or endogenously produced by the cell, modulate the GABA-R by drastically altering the binding characteristics of various GABA-R ligands, underlying the importance of the lipid environment for this process (Schwartz et al., 1988; Koenig and Martin, 1992; Samochocki and Strosznajder, 1993; Witt and Nielsen, 1994; Witt et al., 1996). FFA acting on the GABA-R must have at least one C-C double bond and a carbon length of 16-22 C (Witt and Nielsen, 1994). The effect of FFA on GABA/benzodiazepine receptor $\mathrm{Cl}^{-}$ channel complex from mammalian, avian, amphibian, and fish species was studied in vitro (Witt and Nielsen, 1994). Different effects of unsaturated FFA were observed on $\left[{ }^{3} \mathrm{H}\right]$ diazepam and $\left[{ }^{3} \mathrm{H}\right]$ muscimol binding: FFA enhanced ligand binding in the case of mammalian and amphibian receptors; of 17 fish species studied, 11 species presented weak stimulation of ligand binding, 4 species did not show augmented stimulation and 2 species exhibited inhibition; in the 10 bird species studied, only weak enhancement of $\left[{ }^{3} \mathrm{H}\right]$ muscimol binding was found, whereas $\left[{ }^{3} \mathrm{H}\right]$ diazepam binding was similar to mammal species (Witt and Nielsen, 1994). These results point to phylogenetic differences in the receptor that might account for the differences in FFA modulation. Again it is possible to consider a direct or an indirect FFA mechanism for GABA-R modulation. The argument for indirect effects rests on the fact that ontogenetic differences also involve changes in membrane composition, as fish membranes are composed mainly of phospholipids with unsaturated fatty acids and, hence, a further fluidizing effect by exogenously added unsaturated FFA is unlikely (Witt and Nielsen, 1994). However, an increase in the temperature of the binding assay, which induced an increment in membrane fluidity, did not alter the unsaturated FFA effect on ligand binding to GABA-R. Evidence pointing to a direct mechanism included the study of FFA effects on distinct recombinant human $\mathrm{GABA}_{\mathrm{A}}-\mathrm{R}$ complexes formed by different subunit compositions $(\alpha, \beta$, and $\gamma$ subunits) where a modulation of the ligand binding by FFA was dependent on the subunit combination. These results suggest the existence of specific amino acid sequences in the $\alpha$ subunits that confer FFA sensitivity to the GABA $-\mathrm{R}$ (Witt et al., 1996, 1999). Additional data suggest that FFA bind to specific sites, unleashing apparently independent responses: the rapid potentiation of the GABA currents and the increased desensitization of the GABA$\mathrm{R}$ complex, which requires the presence of the $\gamma 2$ subunit (Nabekura et al., 1998). Thus, the combination of different factors, such as the type and concentration of FFA plus the various combinations of GABA-R subunits in the same neuron result in a broad spectrum of potential modulatory mechanisms which might affect GABA responses in the CNS. The mechanism of FFA modulation on $\mathrm{GABA}_{\mathrm{A}}$ receptors -activation of second messenger systems- appears to be shared by another inhibitory ligand-gated ion channel, the glycine receptor (Kloda et al., 2007).

\section{Nicotinic Acetylcholine Receptors (nAChRs)}

"A protein isolated from Naja naja siamensis venom on the basis of its phospholipase A activity inhibits acetylcholine receptor function in post-synaptic membrane vesicles from Torpedo californica" (Andreasen and McNamee, 1977). This was the first evidence linking FFA with nAChR function. Shortly after, it was demonstrated that incorporation of unsaturated fatty acids or lyso-phosphatidylcholine into Torpedo membranes also inhibited nAChR function whereas lyso-phosphatidylethanolamine and most saturated FFA caused no effect (Andreasen et al., 1979). This inhibitory effect could be reversed and/or prevented by treatment with bovine serum albumin. Spin-labeled fatty acids also inhibited Torpedo $\mathrm{nAChR}$, the magnitude of this effect being largely dependent on the position of the nitroxide group along the hydrocarbon chain (Andreasen and McNamee, 1980). The FFA inhibitory effect on nAChR function was attributed to the perturbation of protein-lipid interactions, and the magnitude of the effect was found to depend on FFA structure (Andreasen and McNamee, 1980). Alterations in nAChR function by FFA, particularly linolenic acid, or by phospholipase A2 hydrolysis products were directly correlated with perturbations of $\mathrm{nAChR}$ structure (Villar et al., 1988).

We analyzed the effect of four long-chain free fatty acids (AA, 20:4; DHA, 22:6; palmitic acid, 16:0; and nonadecanoic acid, 19:0) on the function of the acetylcholine receptor (nAChR) at the single-channel level (Bouzat and Barrantes, 1993a). The effect had a rapid onset and only very brief opening events were apparent after FFA application. The modification appeared not to be critically dependent on the degree of FFA saturation. In intact cells, fatty acids could reach and affect nAChR channels in the plasmalemma under the patch pipette when added from outside the patch-clamped area, suggesting i) that fatty acids diffused laterally and ii) the possibility that the AChR-lipid interface was the site of action of FFA (Bouzat and Barrantes, 1993a).

Free fatty acids (FFA) display the highest affinity for the native membrane-bound $\mathrm{ACCh}$ among all lipids studied to date (Marsh and Barrantes, 1978; Ellena et al., 1983; Dreger et al., 1997; Mantipragada et al., 2003). We subsequently disclosed the occurrence of independent sites for phospholipids and sterols in native nAChR membranes (Antollini and Barrantes, 1998), and found that these discrete sites were both accessible to FFA. From fluorescence quenching studies using nitroxide spin labels we also tentatively concluded that the sites were located at a shallow depth close to the phospholipid polar head region in native nAChR membranes (Barrantes et al., 2000). However, despite being located at the same site, each class of FFA differs in its effect on the physical properties of the membrane depending on its structure. Using the polarity-sensitive fluorescence probe Laurdan, it was possible to distinguish between saturated FFA, 
which induced a small increase in membrane order, and cisunsaturated fatty acids, which caused a clear decrease of the lipid order. Double-bond isomerism could also be distinguished: oleic acid (18:1cis) induced a net disordering effect, whereas elaidic acid (18:1trans) produced no changes in membrane order (Antollini and Barrantes, 2002). These data lead us to suggest that it is the direct action of FFA at the lipid-protein interface, displacing essential lipids from their sites, rather than changes in bulk properties, such as membrane fluidity, that accounts for the inhibitory effect of FFA on nAChR function.

Two types of lipid sites have been described to be present in integral membrane proteins in general, and at the lipid-nAChR interface in particular: annular and non-annular sites. Annular sites constitute the first shell of lipids surrounding the protein and interact with the protein in a relatively less specific manner; the rate of exchange between annular shell lipid and bulk membrane lipid is relatively fast, in the order of $1-5 \times 10^{8} \mathrm{~s}^{-1}$ (Marsh and Barrantes, 1978; Barrantes, 2004). Non-annular lipid sites involve spaces between TM helices and between subunits in multisubunit proteins (Lee, 2004). Non-annular lipids are considered essential for protein activity, and display higher specificity for the protein. The rate of exchange of non-annular lipids with bulk lipids has not yet been experimentally determined, but is presumably sluggish, and in any case much slower than that of annular lipids, as a result of the high specificity of the interaction between non-annular lipids and the protein (Lee, 2004). On the basis of competition studies, early studies suggested that non-annular lipids were associated with binding sites to which cholesterol is bound but phospholipids are not (Jones and McNamee, 1988). We demonstrated that both endogenous FFA generated by phospholipase A2 from Torpedo native membranes and AA exogenously added to these membranes localize at both annular and non-annular sites at the lipid-protein interface (Fernández Nievas et al., 2007). Furthermore, we found that nAChR conformational transitions between the resting (R) state and the desensitized (D) state may entail a rearrangement of the nAChR TM region involving the occlusion of non-annular sites at the lipid-protein interface or simply decreased lipid efficacy in accessing such sites (Fernández Nievas et al., 2007; Figure 1).

Taking advantage of the different affinities that the fluorescence dye crystal violet $(\mathrm{CrV})$ displays for the resting $(\mathrm{R})$ and desensitized (D) states of the nAChR we observed that the dissimilar effects that FFA exert on the receptor conformational states depend on the structural characteristics of the fatty acids (Fernández Nievas et al., 2008). Whereas cis-FFA increased membrane polarity, trans-FFA and saturated FFA caused essentially no changes in this property. Only cis-FFA drove the $\mathrm{nAChR}$ out of the $\mathrm{R}$ state in the absence of agonist; we hypothesized that most likely direct contacts between the FFA and $\mathrm{TM}$ portions of the $\mathrm{nAChR}$ are responsible for driving the receptor out of the $\mathrm{R}$ state and, hence, inhibit its function. cis-FFA caused a second effect on membrane-bound nAChRs: they prevented the receptors from reaching the $\mathrm{D}$ state in the presence of agonist. This lack of transition to the D state of the $\mathrm{nAChR}$ could be mimicked by raising the temperature, which disorders the membrane bilayer, or by treatment with PLA2, which decreases the polarity of the membrane, two conditions that do not perturb the $\mathrm{R}$ state of the nAChR. The second effect seems not to depend on the presence of specific molecules at the lipid-nAChR interface but rather to be unspecific, mainly associated with changes in the physical state of the bulk membrane. Thus, whereas foreign molecules at the lipid-protein interface probably modify the "activation gate" of the nAChR-associated channel, leading to an intermediate D state, changes in the physical state of the membrane (particularly changes in membrane order or polarity) are likely to perturb the "desensitization gate" (Fernández Nievas et al., 2008; Figure 2). A previous study with single cells obtained from flexor digitorum brevis muscles of adult male mice also correlated $\mathrm{nAChR}$ functional inhibition with $\mathrm{nAChR}$ protein conformation (Nojima et al., 2000). These authors demonstrated that AA, and prostaglandin D2 (PGD2) or its metabolites, cooperatively accelerate desensitization of the $\mathrm{nAChR}$. The explanation provided invoked the activation of PKC by AA and PGD2 in this mechanism. However, the experiments of Fernández Nievas et al. (2008), performed in isolated nAChR-rich plasma membranes in the absence of phosphorylation (absence of ATP and insufficient $\mathrm{Mg}^{2+}$ concentration; Safran et al., 1990) clearly demonstrated the inhibition and conformational changes of the nAChR, suggesting that the inhibition and desensitization of the nAChR by FFA does not involve PKC activity. Putting all the information together reinforces the view that there is more than one mechanism of action involved in the modulation of $\mathrm{nAChR}$ function by FFA.

In order to further dissect the mechanisms of action of cis-unsaturated FFA on the native membrane-bound Torpedo nAChR, we resorted to the use of five different monounsaturated fatty acids with the same number of carbon atoms (cis-6-18:1, cis9-18:1, cis-11-18:1, cis-13-18:1, and trans-9-18:1) (Perillo et al., 2012). Four out of five 18:1 FFA tested (cis-9-18:1, cis-11-18:1, cis-13-18:1, and trans-9-18:1) were found to localize at both annular and non-annular sites; only cis-6-18:1 was found in annular sites. Membrane order was found to undergo a very slight and saturable decrease in the presence of the transunsaturated FFA, whereas all cis-monounsaturated FFA tested caused membrane order perturbations dependent on the position of the double bond. The largest effect was observed when the double bond was near the middle of the acyl chain. Patch-clamp experiments disclosed the inhibition of nAChR currents only with cis-9-18:1 or cis-6-18:1. All unsaturated FFA prevented the $\mathrm{nAChR}$ from reaching the $\mathrm{D}$ state in the presence of agonist but only cis-9-18:1, cis-11-18:1, and cis-13-18:1 drove the AChR out of the $\mathrm{R}$ state in the absence of agonist. Finally, only cismonounsaturated FFA caused a local topological change in the nAChR $\gamma$ TM4 segment (cis-6-18:1 to a lesser extent) (Table 1). Taken together, these data led us to conclude that the position of the torsion angle of unsaturated FFA is a key factor in channel blockage. If one takes into consideration that (i) the sequence of structural events coupling ligand binding to channel gating begins with movements at the ligand-binding loops, is followed by the displacement of loops located at the interface between the extracellular ligand binding domain and the TM domain, the 

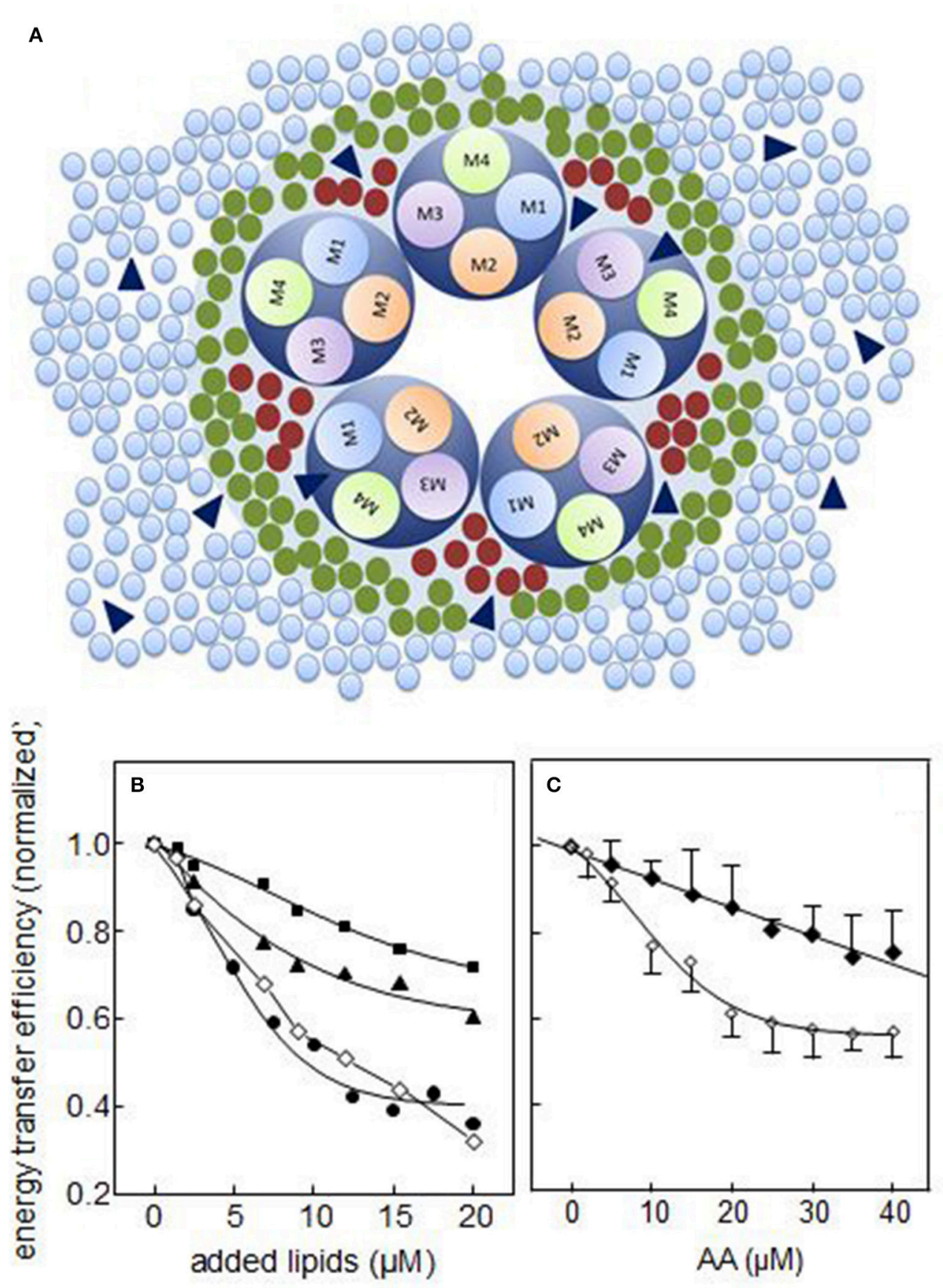

FIGURE 1 | (A) Schematic diagram of a direct mechanism of action of FFA on nAChR function. The scheme illustrates the nAChR-lipid relationship in a receptor-rich membrane, outlining the spatial distribution of the transmembrane segments (TM1, TM2, TM3, and TM4) and the surrounding lipid shell. Three lipid topologies are indicated: non-annular lipids (bordeaux $\bullet$ ), annular lipids (green $\bullet$ ) and bulk lipids (light blue $\bullet$ ). FFA (blue $\mathbf{\Delta}$ ) can be found in any of these three domains. (B,C) Experimental studies on annular and non-annular sites using the efficiency ( $E$ ) of the Förster resonance energy transfer (FRET) process between the intrinsic fluorescence of $T$. californica $n A C h R$ membranes and the extrinsic fluorescent probe Laurdan; (B) in the presence of increasing concentrations of DOPC ( $\mathbf{\square})$,

cholesterol hemisuccinate (CHS, $\mathbf{\Lambda})$, and oleic acid $(\bullet)$, where the symbol $(\diamond)$ corresponds to the sum of $E$ of DOPC and CHS (from Antollini and Barrantes, 1998$)$ and (C) in the presence of increasing concentrations of arachidonic acid with the nAChR in the resting ("R", $\diamond)$ or the desensitized ("D", $\bullet$ ) state. The latter was generated by incubation of the membrane with $1 \mathrm{mM}$ carbamoylcholine prior to the fluorescence measurements (From Fernández Nievas et al., 2007).

subsequent tilting/bending of the pore-lining M2 helix, and ends with movements of M4, M3, and M1 helices in the TM domain (Mitra et al., 2004; Auerbach, 2005), and (ii) that FFA might exert their action by an allosteric mechanism at the lipid-nAChR protein interface, those FFA with the double bond at a shallow position in the membrane probably share the topological loci of 


\section{$R+2 A \Leftrightarrow A R+A \Leftrightarrow A_{2} R \Leftrightarrow A_{2} R^{*}$ 金 企 金 金 \\ $D+2 A \Leftrightarrow A D+A \Leftrightarrow A_{2} D \Leftrightarrow A_{2} D^{*}$}

FIGURE 2 | Sequential model of the nAChR activation equilibrium. The model considers that each state of channel activation has a corresponding desensitized state (Dilger and Liu, 1992): $R$ is the nAChR in the resting state, A the agonist and RA and RA2 represent the nAChR with one or two agonist molecules bound, respectively, and RA2* is the biliganded nAChR in a transient active open configuration; $\mathrm{D}, \mathrm{AD}, \mathrm{A} 2 \mathrm{D}$, and $\mathrm{A} 2 \mathrm{D}^{*}$ are the corresponding isoforms in the desensitized, non-conductive states, respectively. This allosteric equilibrium can be affected e.g., by single-point mutations and exposure to some drugs (From Fernández Nievas et al., 2008).

the conserved core structure for $\mathrm{AAChR}$ gating and hence could perturb this synchronous mechanism (Perillo et al., 2012).

Changes in membrane lipid composition (Criado et al., 1984; Sunshine and McNamee, 1994; Baenziger et al., 2000; da Costa et al., 2002) and/or the presence of exogenous hydrophobic molecules like steroids and fatty acids (Andreasen and McNamee, 1980; Villar et al., 1988; Bouzat and Barrantes, 1993a,b, 1996; Lasalde et al., 1995; Nurowska and Ruzzier, 1996; Santiago et al., 2001; Garbus et al., 2001, 2002) affect AChR function. Individual amino acid mutations in the lipid-facing outer ring (M4) of the nAChR TM domain also modulate nAChR function (Lee et al., 1994; Lasalde et al., 1996; Ortiz-Miranda et al., 1997; Bouzat et al., 1998; Tamamizu et al., 1999, 2000), a clear indication that although far away from the agonist sites and from the ion channel, the M4 TM segment, the only member of the outermost TM ring (Barrantes, 2003), effectively influences $\mathrm{nAChR}$ function. In this sense, M4 would behave as a sensor of the lipid-protein environment unleashing a signal to the M2 channel region, probably initiated by the induction of changes in the topology of the outer ring and ultimately causing a conformational change of the whole AChR (Xu et al., 2005; Fernández Nievas et al., 2007, 2008; Perillo et al., 2012; Barrantes, 2015).

Contrary to the rapid inhibitory effect described above, a potentiation effect of AA on Torpedo $\mathrm{nAChR}$ expressed in Xenopus oocytes, lasting over $30 \mathrm{~min}$ after FFA washing, has been reported (Ikeuchi et al., 1996). This effect resembles the dual action of FFA on $\mathrm{Na}^{+}$channels described in previous sections. Pretreatment with PKC inhibitors did not counteract the FFA inhibition but abolished the potentiation effect. However, experiments performed with mutant nAChR lacking PKC phosphorylation sites showed no current blocking effect of AA and a current potentiation greater than in the control condition. Together, these results pointed to two different and independent mechanisms: a short-term blocking mechanism through direct action of AA on nAChR PKC phosphorylation sites, rather than through an effect on the membrane environment; and a long-term potentiating mechanism caused by PKC activation not involving nAChR phosphorylation. This second mechanism must include an unknown pathway related to AA-regulated PKC. Different results were observed depending on the FFA structure. Treatment with linoleic (18:2) or linolenic (18:3) acids caused similar dual effects on Torpedo nAChR; however, the long-term potentiation was not evident in mutant nAChR, indicating that these FFA, in contrast to AA, did in fact potentiate nAChR via its PKC phosphorylation site (Nishizaki et al., 1997a). On the other hand, current potentiation by treatment with oleic acid (18:1) was not hindered by PKC inhibitors but fully inhibited by KN-62, a calmodulin-dependent protein kinase II (CaMKII) inhibitor, suggesting that oleic acid enhances $\mathrm{nAChR}$ currents by activation of CaMKII, independently of the PKC pathway (Nishizaki et al., 1997b). This can be accounted for by the explanation provided by Gérczy et al. (2012), pointing to the AA selectivity of certain PKC isoforms over several other signal-transduction mechanisms. Lysophosphatic acid also enhances Torpedo nAChR currents both in control and in mutant nAChRs lacking PKC phosphorylation sites; however, the potentiation was also completely blocked by GF109203X (Nishizaki and Sumikawa, 1997). These authors suggested that lysoPA probably potentiates nAChR currents by pertussis toxin-insensitive G-protein and activation of $\mathrm{Ca}^{2+}$-dependent/independent PKCs with subsequent phosphorylation of the receptors and, additionally, by an unknown factor or process activated by PKC activation. Saturated FFA with less than 20 $\mathrm{C}$ atoms also potentiate $\mathrm{nAChR}$ currents with the participation of PKC, stearic acid (18:0) being the most potent FFA in this respect (Ohta et al., 2003). A comprehensive study of the importance of the FFA structure (Yaguchi et al., 2005) concluded that FFA modulation of nAChR current could not be simply explained by the number and position of the cis-double

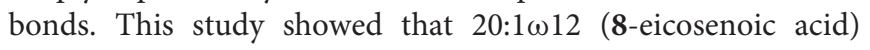
potentiated the currents without depression, whereas 20:1 115 (5-eicosenoic acid) and 20:1 $\omega 9$ (11-eicosenoic acid) elicited only the depression component, suggesting that cis-double bond at the 8th position plays a role in the potentiation and at the 5th or 11th position in the depression. This rule agrees

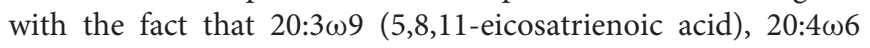
(5,8,11,14-eicosatetraenoic acid), and C20:5 $\omega 3$ (5,8,11,14,17eicosapentaenoic acid) induced a transient inhibition followed by enhancement of the currents, whereas $20: 3 \omega 6 \quad(8,11,14-$ eicosatrienoic acid) induced only nAChR depression and not potentiation (Yaguchi et al., 2005). It should be noted, however, that 20:2 $\omega 6$ (11,14-eicosadienoic acid) has no double-bonds at crucial positions and it has a dual effect on nAChR currents. The carboxy-terminal group appears to play a critical role in the potentiation of the nAChR, as this group is necessary for PKC$\varepsilon$ activation; replacement of $\mathrm{COOH}$ in linoleic acid by $\mathrm{CONH} 2$ (linoleoylamide) only caused the depression effect (Yaguchi et al., 2005).

The work of Vijayaraghavan et al. (1995) was the first demonstration that FFA also modulate neuronal-type nAChRs. Using chick ciliary ganglion neurons these authors showed that seconds of incubation with AA sufficed to inhibit neuronal $\mathrm{nAChR}$ with a distinct and largest effect on the a7-type nAChR. This inhibition was not restricted to AA but also included other FFA in a structure-dependent manner: saturated or cis/trans monounsaturated FFA showed little or no effect; FFA having two or three double bonds exhibited inhibitory 
TABLE 1 | Summary of effects produced by different FFAs on the nAChR (Perillo et al., 2012).

\begin{tabular}{|c|c|c|c|c|c|}
\hline & $\begin{array}{c}\text { Petroselenic acid } \\
(18: 1 \text { cis-6) }\end{array}$ & $\begin{array}{l}\text { Oleic acid } \\
(18: 1 \text { cis-9) }\end{array}$ & vaccenic acid & Octadecanoic acid & Elaidic acid (18:1 trans-9) \\
\hline Sites at lipid-nAChR interface & $A^{a}$ & $A+N A^{b}$ & $A+N A$ & $A+N A$ & $A+N A$ \\
\hline inhibition of $n A C h R$ function & + & ++ & - & - & - \\
\hline GP modification & ++ & +++ & ++ & + & - \\
\hline Anisotropy modification & + & +++ & ++ & ++ & - \\
\hline nAChR TM4 perturbation & + & ++ & ++ & ++ & - \\
\hline R-state perturbation & - & ++ & ++ & ++ & - \\
\hline D-state perturbation & ++ & ++ & + & + & + \\
\hline
\end{tabular}

The CPK structures of the FFAs studied are shown for clarity: the broken line shows the position of the cis double bond and the arrow indicates the position of the trans double bond. ${ }^{a} A$, annular sites; ${ }^{b} N A$, non-annular sites.

effects, and AA displayed maximal effect. The authors concluded that the inhibition must be caused by a direct action of the FFA on the nAChR or through the membrane, discarding the possible action of AA metabolites or the activation of PKC. Minota and Watanabe (1997) also showed that AA directly inhibits $\mathrm{nAChR}$ in bullfrog sympathetic ganglia, and that its metabolites do not play a major part in this inhibition. Two general possibilities were postulated to account for this mechanism: (i) AA binds to allosteric sites of the nAChR -one possibility being a site in the channel pore- thus inhibiting synaptic transmission without affecting the binding of ACh to the receptor; or (ii) AA perturbs the local environment of the receptors by partitioning into the membrane and thereby indirectly inhibiting receptor function. Nishizaki et al. (1998) indicated that neuronal $\mathrm{nAChRs}$ display short-term depression and/or long-term enhancement of nAChR currents depending on the biological source of the neuronal nAChR. Treatment of chick $\alpha 7$ nAChR with AA caused only a depression effect (in accordance with Vijayaraghavan et al. (1995)) whereas in the case of rat $\alpha 7 \mathrm{nAChR}$ the same treatment caused exclusively a potentiation effect by PKC activation. This strongly suggests a relation between FFA effect and nAChR structure; the different response to AA may probably be due to structural differences between receptors. Further studies with rat $\alpha 7$ and $\alpha 2 \beta 4 \mathrm{nAChR}$ showed that AA increases glutamate release by potentiating the activity of presynaptic nAChRs, predominantly $\alpha 7 \mathrm{nAChR}$, under the influence of PKC, an effect not related to CaMKII activity (Nishizaki et al., 1999). Stearic acid has also been shown to potentiate $\alpha 7 \mathrm{nAChR}$ currents, with the involvement of PKC in this potentiation (Ohta et al., 2003). The latter work demonstrated that although stearic acid enhances activity of already active PKC- $\varepsilon$ it does not directly activate this enzyme.
Studies of the FFA modulation of different proteins through $\mathrm{PKC}$ indicate that, in some cases, the mechanism involves not a direct PKC activation but an increased expression and altered subcellular distribution of PKC. It is known that translocation of PKC isoforms is generally regarded to be indicative of their activation. Li et al. (2010) explained the induced pulmonary artery (PA) contraction by hypoxia through an important increment in both the RNA levels and protein expression of PKC- $\delta$ and PKC- $\varepsilon$ induced by 15-hydroxyeicosatetraenoic acid (HETE). In this case, AA is metabolized by 15-lipoxygenase, which is up-regulated by hypoxia, to 15-HETE which causes pulmonary artery (PA) constriction by activation of PKC- $\delta$ and PKC- $\varepsilon$. A similar profile was described in HEK293 cells, where AA displays a biphasic effect on $\mathrm{Ca}^{2+}$ signaling: at low concentrations, AA suppresses both $\mathrm{Ca}^{2+}$ release and $\mathrm{Ca}^{2+}$ influx responses to agonist; whereas at high concentrations, AA potentiates $\mathrm{Ca}^{2+}$ release and $\mathrm{Ca}^{2+}$ entry response (Chen et al., 2012). These authors postulated that AA induces PKC $\alpha$ and PKC $\beta I I$ redistribution at the plasma membrane, and that at higher AA concentrations trafficking of PKC $\beta I$ and PKC $\beta I$ to the endoplasmic reticulum also occurred. A totally opposite effect was described in a study of the immunomodulatory properties of PUFA in phagocyte function (Gorgani et al., 2011). These authors demonstrated that AA causes a significant decrease in CRIg expression at both the mRNA and protein levels, and that this down-regulation is dependent on PKC activation by AA excluding the possibility that AA could exert its effect through its metabolism via cyclooxygenase and/or lipoxygenase.

It is important to highlight that the FFA concentrations used in all the studies mentioned here were below the high FFA levels reported in several pathological conditions as a consequence of PLA2 activation and FFA release from plasma membranes. Arachidonate levels in the plasma of malaria patients are in the 
order of $100 \mu \mathrm{M}\left(\approx 33.3 \mu \mathrm{g} \cdot \mathrm{mL}^{-1}\right)$ (Eissen, 1993) and under ischemic conditions these levels can rise to $500 \mu \mathrm{M}, 10$-fold higher than the free AA levels found in normal brain (Yasuda et al., 1985). A 10-fold increment in FFA was also reported in an experimental model of acute lung injury (Arbibe et al., 1998).

More recent studies used FA derivatives to explore in more detail the modulatory mechanism exerted by FFA on $\alpha 7$ nAChR. FR236924, a linoleic acid derivative, was synthesized having cyclopropane rings instead of cis-double bonds. The FA analog induced a long-lasting facilitation of hippocampal neurotransmission, as assessed by the persistent enhancement in the activity of presynaptic nAChRs via a PKC pathway (Tanaka and Nishizaki, 2003; Yamamoto et al., 2005). 4-[4(Z)-hept-1-enyl-phenoxy] butyric acid (HUHS2002) potentiated rat $\alpha 7 \mathrm{nAChR}$ currents, an effect that was not affected by the addition of an inhibitor of PKC but significantly inhibited by an inhibitor of CaMKII (Kanno et al., 2012a). This suggests that HUHS2002 potentiates $\alpha 7 \mathrm{nAChR}$ currents by activation of CaMKII. However, HUHS2002 might indirectly activate CaMKII by inhibiting protein phosphatase 1 (PP1), which normally dephosphorylates and inactivates CaMKII. Another linoleic acid derivative with cyclopropane rings instead of cis-double bonds (DCP-LA) preserved the potentiation effect on nAChR currents, which was abolished by GF109203X, a PKC inhibitor (Kanno et al., 2012b). The DCP-LA effect (a) was significantly inhibited by vesicular transport inhibitors, (b) promoted the translocation of the $\alpha 7 \mathrm{nAChR}$ from the cytosol to the plasma membrane and (c) stimulated $\alpha 7 \mathrm{nAChR}$ delivery toward presynaptic terminals. The evidence suggests that the nAChR current potentiation could arise from the DCP-LA mediated stimulation of $\mathrm{nAChR}$ vesicular transport and the consequent increase in the number of $\mathrm{nAChR}$ targeted to the cell surface (Kanno et al., 2012b). This was the first postulation of PKC control of intracellular $\alpha 7 \mathrm{nAChR}$ trafficking; which PKC targets participate in this regulation is still not known. Subsequent studies showed that DCP-LA significantly increased an association of $4.1 \mathrm{~N}$-a scaffolding protein- with $\alpha 7 \mathrm{nAChR}$; and that this association is partially prevented by GF109203X, an inhibitor of PKC, but independently of $4.1 \mathrm{~N}$ phosphorylation (Kanno et al., 2013). The same study showed for the first time that $4.1 \mathrm{~N}$ is required for translocation of the $\alpha 7 \mathrm{nAChR}$ toward the plasma membrane. Thus, DCPLA could induce an increase in the association of the $\alpha 7$ nAChR with $4.1 \mathrm{~N}$ in a PKC-dependent manner, not caused by $\mathrm{PKC}$ phosphorylation of $4.1 \mathrm{~N}$ or by phosphorylation of the receptor. Probably DCP-LA, by activating PKC, phosphorylates an unknown factor that enhances the association of $4.1 \mathrm{~N}$ with the $\alpha 7$ nAChR (Kanno et al., 2013). Thus, the evidence described in the last paragraphs point to a novel pathway linking lipid signaling to $\alpha 7 \mathrm{nAChR}$ responses, as is graphically summarized in Figure 3.

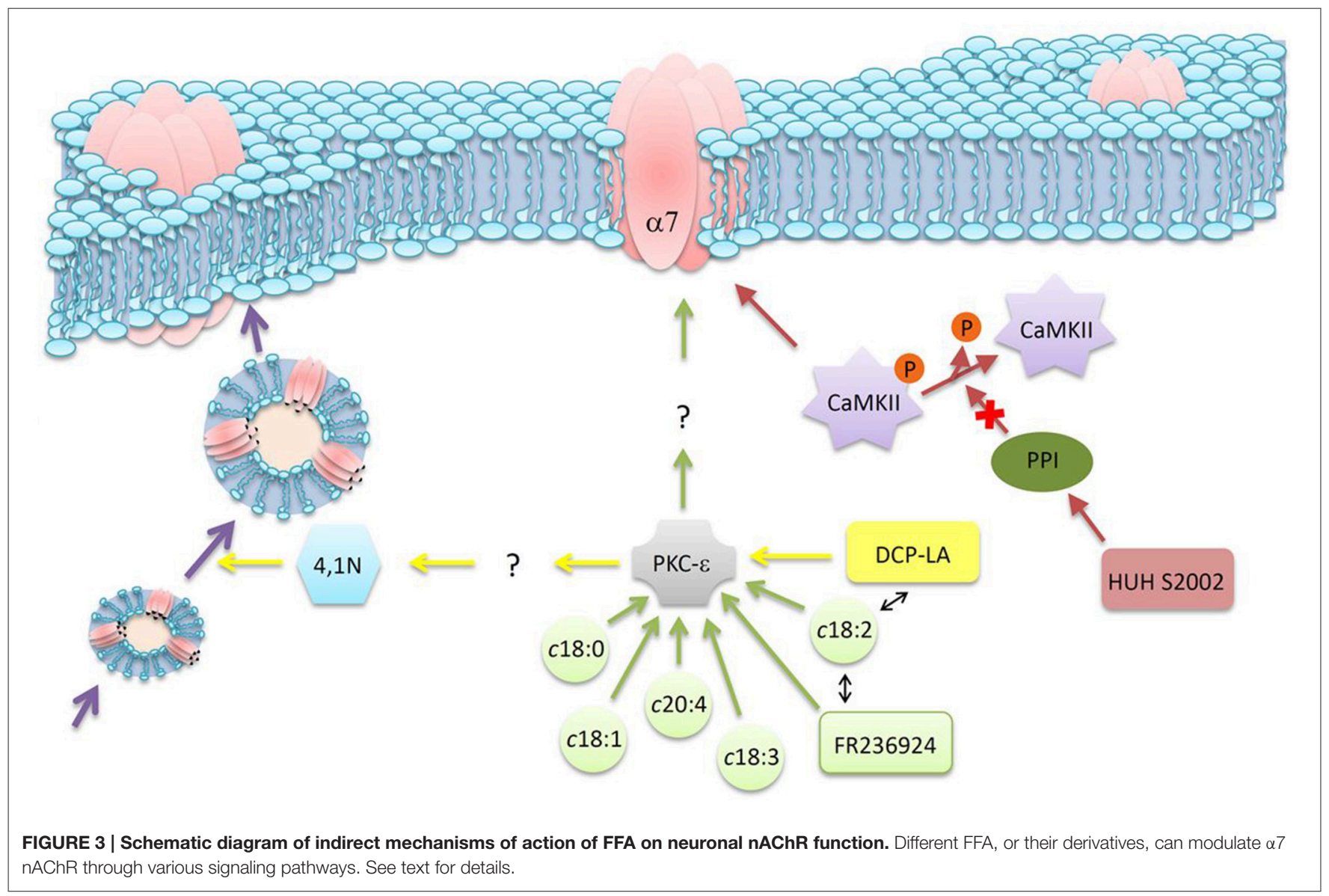


One avenue that needs to be explored in greater detail is the involvement of abnormalities of FA metabolism in brain diseases. Circulating long-chain fatty acids act as signals of nutrient surplus in the hypothalamus. Furthermore, pharmacological and/or genetic inhibition of FA synthase, AMP-activated protein kinase and carnitine palmitoyl transferase 1 (CPT1) results in marked decreases in feeding levels and loss of body weight in rodents (López et al., 2007). CPT1c, the recently discovered brain isoform of the multiprotein complex enzyme carnitine palmitoyl transferase, is predominantly localized in regions involved in the regulation of food intake, such as the hypothalamus, emotion and reward systems -the amygdala- and learning and memory, the hippocampus. CPT activity has been associated with dysregulation of insulin equilibrium in brain and related metabolic dysfunctions, and implicated in the evolution of Parkinson's and Alzheimer's diseases (Virmani et al., 2015).

\section{CONCLUSIONS}

When analyzing the effects of FFA on a variety of ion channels, one of the first clear outcomes is that different FFA exert distinct effects, or no effect at all, on a same channel protein, whereas similar FFA may cause diverse effects on different proteins, even if the latter are very closely related from a phylogenetic point of view. In spite of these apparent discrepancies, it is

\section{REFERENCES}

An, R. H., Wang, X. L., Kerem, B., Benhorin, J., Medina, A., Goldmit, M., et al. (1998). Novel LQT-3 mutation affects $\mathrm{Na}^{+}$channel activity through interactions between alpha- and betal-subunits. Circ. Res. 83, 141-146. doi: 10.1161/01.RES.83.2.141

Anderson, M. P., and Welsh, M. J. (1990). Fatty acid inhibit apical membrane chloride channels in airway epithelia. Proc. Natl. Acad. Sci. U.S.A. 87, 7334-7338. doi: 10.1073/pnas.87.18.7334

Andreasen, T. J., Doerge, D. R., and McNamee, M. G. (1979). Effects of phospholipase A2 on the binding and ion permeability control properties of the acetylcholine receptor. Arch. Biochem. Biophys. 194, 468-480. doi: 10.1016/0003-9861(79)90641-6

Andreasen, T. J., and McNamee, M. G. (1977). Phospholipase A inhibition of acetylcholine receptor function in Torpedo californica membrane vesicles. Biochem. Biophys. Res. Commun. 79, 958-965. doi: 10.1016/0006-291X(77)91203-7

Andreasen, T. J., and McNamee, M. G. (1980). Inhibition of ion permeability control properties of acetylcholine receptor from Torpedo californica by long-chain fatty acids. Biochemistry 30, 4719-4726. doi: 10.1021/bi00 $561 \mathrm{a} 027$

Antollini, S. S., and Barrantes, F. J. (1998). Disclosure of discrete sites for phospholipid and sterols at the protein-lipid interface in native acetylcholine receptor-rich membrane. Biochemistry 37, 16653-16662. doi: 10.1021/bi9808215

Antollini, S. S., and Barrantes, F. J. (2002). Unique effects of different fatty acid species on the physical properties of the Torpedo acetylcholine receptor membrane. J. Biol. Chem. 277, 1249-1254. doi: 10.1074/jbc.M106618200

Arbibe, L., Koumanov, K., Vial, D., Rougeot, C., Faure, G., Havet, N., et al. (1998). Generation of lyso-phospholipids from surfactant in acute lung injury is mediated by Type-II phospholipase A2 and inhibited by a direct surfactant protein A-phospholipase A2 protein interaction. J. Clin. Invest. 102, 1152-1160. doi: 10.1172/JCI3236

Atkin, O. K., and Macherel, D. (2009). The crucial role of plant mitochondria in orchestrating drought tolerance. Ann. Bot. 103, 581-597. doi: $10.1093 / \mathrm{aob} / \mathrm{mcn} 094$ clear that almost all FFA that modulate the ion channel directly, i.e., not through their metabolites or signaling cascades, act by direct physical contact with the protein. Direct mechanisms consequently put both FFA structure and channel structure particularly those amino acids that participate in the interactionat center stage. Amino acid residues involved in the recognition of FFA are apparently sensitive to the length, isomerism and saturation of the FFA. It is thus mandatory to identify and characterize in detail the structure of the intervening binding site(s) in the protein and the counteracting FFA structure to unravel the different inhibitory or stimulatory modalities at the molecular level and eventually contribute to the design of new lipid-based modulatory drugs targeting specific channel proteins.

\section{AUTHOR CONTRIBUTIONS}

Experimental work quoted in this review was supported by grants PICT 2011-0604 from FONCYT, Ministry of Science and Technology and PIP No. $\mathrm{N}^{\circ}$ 112-201101-01023 from the National Scientific and Technical Research Council of Argentina (CONICET) to FJB. and grants PIP 112-201101-00239 from CONICET, PGI 24/B217 from Universidad Nacional del Sur, and PICT 2012-2746 from MINCYT to SSA. The costs of publication were defrayed from grant PIP No. 112-201101-01023 from CONICET to FJB.

Auerbach, A. (2005). Gating of acetylcholine receptor channels: Brownian motion across a broad transition state. Proc. Natl. Acad. Sci. U.S.A. 102, 1408-1412. doi: 10.1073/pnas.0406787102

Baenziger, J. E., Morris, M. L., Darsaut, T. E., and Ryan, S. E. (2000). Effect of membrane lipid composition on the conformational equilibria of the nicotinic acetylcholine receptor. J. Biol. Chem. 275, 777-784. doi: 10.1074/jbc.275.2.777

Barrantes, F. J. (2003). Modulation of nicotinic acetylcholine receptor function through the outer and middle rings of transmembrane domains. Curr. Opin. Drug Discov. Devel. 6, 620-632.

Barrantes, F. J. (2004). Structural basis for lipid modulation of nicotinic acetylcholine receptor function. Brain Res. Brain Res. Rev. 47, 71-95. doi: 10.1016/j.brainresrev.2004.06.008

Barrantes, F. J. (2015). Phylogenetic conservation of protein-lipid motifs in pentameric ligand-gated ion channels. Biochim. Biophys. Acta. Biomembr. 1848, 1796-1805. doi: 10.1016/j.bbamem.2015.03.028

Barrantes, F. J., Antollini, S. S., Blanton, M. P., and Prieto, M. (2000). Topography of nicotinic acetylcholine receptor membrane-embedded domains. J. Biol. Chem. 275, 37333-37339. doi: 10.1074/jbc.M005246200

Blin, S., Ben Soussia, I., Kim, E. J., Brau, F., Kang, D., Lesage, F., et al. (2016). Mixing and matching TREK/TRAAK subunits generate heterodimeric K2P channels with unique properties. Proc. Natl. Acad. Sci. U.S.A. 12, 4200-4205. doi: $10.1073 /$ pnas. 1522748113

Blobe, G. C., Khan, W. A., and Hannun, Y. A. (1995). Protein kinase C: cellular target of the second messenger arachidonic acid? Prostaglandins Leukot. Essent. Fatty Acids 52, 129-135. doi: 10.1016/0952-3278(95)90011-X

Blondeau, N., Widmann, C., Lazdunski, M., and Heurteaux, C. (2002). Polyunsaturated fatty acids induce ischemic and epileptic tolerance. Neuroscience 109, 231-241. doi: 10.1016/S0306-4522(01)00473-0

Boden, G. (2008). Obesity and free fatty acids (FFA). Endocrinol. Metab. Clin. Noth. Am. 37, 635-646. doi: 10.1016/j.ecl.2008.06.007

Börjesson, S. I., and Elinder, F. (2011). An electrostatic potassium channel opener targeting the final voltage sensor transition. J. Gen. Physiol. 137, 563-577. doi: 10.1085/jgp.201110599

Börjesson, S. I., Hammarström, S., and Elinder, F. (2008). Lipoelectric modification of ion channel voltage gating by polyunsaturated fatty acids. Biophys. J. 95, 2242-2253. doi: 10.1529/biophysj.108.130757 
Börjesson, S. I., Parkkari, T., Hammarström, S., and Elinder, F. (2010). Electrostatic tuning of cellular excitability. Biophys. J. 98, 396-403. doi: 10.1016/j.bpj.2009.10.026

Bouzat, C., and Barrantes, F. J. (1993a). Effects of long-chain fatty acids on the channel activity of the nicotinic acetylcholine receptor. Recept. Channels 1, 251-258.

Bouzat, C., and Barrantes, F. J. (1993b). Hydrocortisone and 11-desoxycortisone modify acetylcholine receptor channel gating. Neuroreport 4, 143-146. doi: 10.1097/00001756-199302000-00007

Bouzat, C., and Barrantes, F. J. (1996). Modulation of muscle nicotinic acetylcholine receptors by the glucocorticoid hydrocortisone. Possible allosteric mechanism of channel blockade. J. Biol. Chem. 271, 25835-25841. doi: $10.1074 /$ jbc.271.42.25835

Bouzat, C., Roccamo, A. M., Garbus, I., and Barrantes, F. J. (1998). Mutations at lipid-exposed residues of the acetylcholine receptor affect its gating kinetics. Mol. Pharmacol. 54, 146-153.

Bränström, R., Aspinwall, C. A., Välimäki, S., Ostensson, C. G., Tibell, A., Eckhard, M., et al. (2004). Long-chain CoA esters activate human pancreatic beta-cell KATP channels: potential role in Type 2 diabetes. Diabetolog. 47, 277-283. doi: 10.1007/s00125-003-1299-x

Brenner, R., G. Perez, J., Bonev, A. D., Eckman, D. M., Kosek, J. C., Wiler, S. W., et al. (2000). Vasoregulation by the betal subunit of the calcium-activated potassium channel. Nature 407, 870-876. doi: 10.1038/35038011

Buckler, K. J., and Honore, E. (2005). The lipid-activated two pore domain $\mathrm{K}^{+}$channel TREK-1 is resistant to hypoxia: implication for ischaemic neuroprotection. J. Physiol. (Lond). 562, 213-222. doi: 10.1113/jphysiol.2004.077503

Casabiell, X., Pandiella, A., and Casanueva, F. F. (1991). Regulation of epidermalgrowth-factor-receptor signal transduction by cis-unsaturated fatty acids. Evidence for a protein kinase C-independent mechanism. Biochem. J. 278, 679-687. doi: 10.1042/bj2780679

Casavant, R. H., Xu, Z., and Dryer, S. E. (2000). Fatty acid-activated $\mathrm{K}^{+}$channels in autonomic neurons: activation by an endogenous source of free fatty acids. J. Neurochem. 74, 1026-1033. doi: 10.1046/j.1471-4159.2000.0741026.x

Chang, Y.-T., Chang, M.-C., Tung, C.-C., Wei, S.-C., and Wong, J.M. (2015). Distinctive roles of unsaturated and saturated fatty acids in hyperlipidemic pancreatitis. World J. Gastroenterol. 21, 9534-9543. doi: 10.3748/wjg.v21.i32.9534

Chen, L., Meng, Q., Yu, X., Li, C., Zhang, C., Cui, C., et al. (2012). Possible mechanisms underlying the biphasic regulatory effects of arachidonic acid on $\mathrm{Ca}^{2+}$ signaling in HEK293 cells. Cell. Sign. 24, 1565-1572. doi: 10.1016/j.cellsig.2012.03.016

Chen, S. G., and Murakami, K. (1992). Synergistic activation of type III protein kinase C by cis-fatty acid and diacylglycerol. Biochem. J. 282, 33-39. doi: 10.1042/bj2820033

da Costa, C. J., Ogrel, A. A., McCardy, E. A., Blanton, M. P., and Baenziger, J. E. (2002). Lipid-protein interactions at the nicotinic acetylcholine receptor. A functional coupling between nicotinic receptors and phosphatidic acid-containing lipid bilayers. J. Biol. Chem. 277, 201-208. doi: 10.1074/jbc.M108341200

Clarke, A. L., Petrou, S., Walsh, J. V. Jr., and Singer, J. J. (2002). Modulation of $\mathrm{BKCa}$ channel activity by fatty acids: structural requirements and mechanism of action. Am. J. Physiol. Cell Physiol. 283, C1441-C1453. doi: 10.1152/ajpcell.00035.2002

Corkey, B. E., Glennon, M. C., Chen, K. S., Deeney, J. T., Matschinsky, F. M., and Prentki, M. (1989). A role for malonyl-CoA in glucose-stimulated insulin secretion from clonal pancreatic beta-cells. J. Biol. Chem. 264, 21608-21612.

Criado, M., Eibl, H., and Barrantes, F. J. (1984). Functional properties of the acetylcholine receptor incorporated in model lipid membranes. Differential effects of chain length and head group of phospholipids on receptor affinity states and receptor-mediated ion translocation. J. Biol. Chem. 259, 9188-9198.

Denson, D. D., Wang, X., Worrell, R. T., and Eaton, D. C. (2000). Effects of fatty acids on BK channels in $\mathrm{GH}_{3}$ cells. Am. J. Physiol. Cell. Physiol. 279, C1211-C1219.

Devor, D. C., and Frizzell, R. A. (1998). Modulation of $\mathrm{K}^{+}$channels by arachidonic acid in T84 cells. I. Inhibition of the $\mathrm{Ca}^{2+}$-dependent $\mathrm{K}^{+}$channel. Am. J. Physiol. 274(Cell Physiol. 43), C138-C148.
Dilger, J. P., and Liu, Y. (1992). Desensitization of acetylcholine receptors in BC3H1 cells. Pfluegers Arch. Eur. J. Physiol. 420, 479-485. doi: 10.1007/BF00374622

Dreger, M., Krauss, M., Hermann, A., and Hucho, F. (1997). Interactions of the nicotinic acetylcholine receptor transmembrane segments with the lipid bilayer in native receptor-rich membranes. Biochemistry 36, 839-847. doi: 10.1021/bi960666z

Duerson, K., White, R. E., Jiang, F., Schonbrunn, A., and Armstrong, D. L. (1996). Somatostatin stimulates BKCa channels in rat pituitary tumor cells through lipoxygenase metabolites of arachidonic acid. Neuropharmacology 35, 949-961. doi: 10.1016/0028-3908(96)00131-1

Eddlestone, G. T. (1995). ATP-sensitive K channel modulation by products of PLA2 action in the insulin-secreting HIT cell line. Am. J. Physiol. 268, C181-C190.

Eissen, E. U. (1993). Significance of plasma free fatty acid levels in human malaria with parasitaemia. Med. Sci. Res. 21, 405-406.

Ellena, J. F., Blazing, M. A., and McNamee, M. G. (1983). Lipid protein interactions in reconstituted membranes containing acetylcholine receptor. Biochemistry 22, 5523-5535. doi: 10.1021/bi00293a012

Fernández Nievas, G. A., Barrantes, F. J., and Antollini, S. S. (2008). Modulation of nicotinic acetylcholine receptor conformational state by free fatty acids and steroids. J. Biol. Chem. 283, 21478-21486. doi: 10.1074/jbc.M800345200

Fernández Nievas, G. A., Barrantes, F. J., and Antollini, S. S. (2007). Conformation-sensitive steroid and fatty acid sites in the transmembrane domain of the nicotinic acetylcholine receptor. Biochemistry 46, 3503-3512. doi: 10.1021/bi061388z

Garbus, I., Bouzat, C., and Barrantes, F. J. (2001). Steroids differentially inhibit the nicotinic acetylcholine receptor. Neuroreport 12, 227-231. doi: 10.1097/00001756-200102120-00010

Garbus, I., Roccamo, A. M., and Barrantes, F. J. (2002). Identification of threonine 422 in transmembrane domain alpha M4 of the nicotinic acetylcholine receptor as a possible site of interaction with hydrocortisone. Neuropharmacology 43, 65-73. doi: 10.1016/S0028-3908(02)00068-0

Garcia, B., Martinez-de-Mena, R., and Obregon, M. J. (2012). Arachidonic acid stimulates DNA synthesis in brown preadipocytes through the activation of protein kinase C and MAPK. Biochim. Biophys. Acta 1821, 1309-1315. doi: 10.1016/j.bbalip.2012.06.011

Gavrilova-Ruch, O., Schönherr, R., and Heinemann, S. H. (2007). Activation of hEAG1 potassium channels by arachidonic acid. Pflugers Arch. Eur. J. Physiol. 453, 891-903. doi: 10.1007/s00424-006-0173-3

Gérczy, T., Oláh, A., Tóth, B. I., Czifra, G., Szöllösi, A. G., Szabó, T., et al. (2012). Protein kinase $C$ isoforms have differential roles in the regulation of human sebocyte biology. J. Inv. Dermatology 132, 1988-1997. doi: 10.1038/jid. 2012.94

Gorgani, N. N., Thathaisong, U., Mukaro, V. R. S., Poungpair, O., Tirimacco, A., Hii, C. S. T., et al. (2011). Regulation of CRIg expression and phagocytosis in human macrophages by arachidonate, dexamethasone, and cytokines. Amer. J. Pathol. 179, 1310-1318. doi: 10.1016/j.ajpath.2011.05.021

Gu, H., Fang, Y. J., He, Y. L., Sun, J., and Zhu, J. (2009). Mei, Y. A. Modulation of muscle rNaV1.4 Na+ channel isoform by arachidonic acid and its nonmetabolized analog. J. Cell. Physiol. 219, 173-182. doi: 10.1002/jcp.21664

Guizy, M., Arias, C., David, M., González, T., and Valenzuela, C. (2005). $\omega-3$ and $\omega-$ 6 polyunsaturated fatty acids block HERG channels. Am. J. Physiol. Cell Physiol. 289, C1251-C1260. doi: 10.1152/ajpcell.00036.2005

Guizy, M., David, M., Arias, C., Zhang, L., Cofán, M., Ruiz-Gutiérrez, V., et al. (2008). Modulation of the atrial specific Kv1.5 channel by the $\mathrm{n}$ 3 polyunsaturated fatty acid, alpha-linolenic acid. J. Mol. Cell. Cardiol. 44, 323-335. doi: 10.1016/j.yjmcc.2007.11.004

Hamilton, K. L., Syme, C. A., and Devor, D. C. (2003). Molecular localization of the inhibitory arachidonic acid binding site to the pore of hIK1. J. Biol. Chem. 278, 16690-16697. doi: 10.1074/jbc.M212959200

Heurteaux, C., Guy, N., Laigle, C., Blondeau, N., Duprat, F., Mazzuca, M. et al. (2004). TREK-1, a $\mathrm{K}^{+}$channel involved in neuroprotection and general anesthesia. EMBO J. 23, 2684-2695. doi: 10.1038/sj.emboj.7600234

Honoré, E., Barhanin, J., Attali, B., Lesage, F., and Lazdunski, M. (1994). External blockade of the major cardiac delayed-rectifier $\mathrm{K}^{+}$channel (Kv1.5) by polyunsaturated fatty acids. Proc. Natl. Acad. Sci. U.S.A. 91, 1937-1941. doi: 10.1073/pnas.91.5.1937 
Horimoto, N., Nabekura, J., and Ogawa, T. (1997). Arachidonic acid activation of potassium channels in rat visual cortex neurons. Neuroscience 77, 661-671. doi: 10.1016/S0306-4522(96)00490-3

Hoshi, T., Wissuwa, B., Tian, Y., Tajima, N., Xu, R., Bauer, M., et al. (2013b). Omega-3 fatty acids lower blood pressure by directly activating largeconductance $\mathrm{Ca}^{2+}$-dependent $\mathrm{K}^{+}$channels. Proc. Natl. Acad. Sci. U.S.A. 110, 4816-4821. doi: 10.1073/pnas.1221997110

Hoshi, T., Xu, R., Hou, S., Heinemann, S. H., and Tian, Y. (2013a). A point mutation in the human Slo1 channel that impairs its sensitivity to omega-3 docosahexaenoic acid. J. Gen. Physiol. 142, 507-522. doi: 10.1085/jgp.201311061

Hudson, B. D., Murdoch, H., and Milligan, G. (2013). Minireview: the effects of species ortholog and SNP variation on receptors for free fatty acids. Mol. Endocrinol. 27, 1177-1187. doi: 10.1210/me.2013-1085

Ikeuchi, Y., Nishizaki, T., Matsuoka, T., and Sumikawa, K. (1996). Arachidonic acid potentiates $\mathrm{ACh}$ receptor currents by protein kinase $\mathrm{C}$ activation but not by receptor phosphorylation. Biochem. Biophys. Res. Commun. 221, 716-721. doi: $10.1006 /$ bbrc. 1996.0662

Jones, O. T., and McNamee, M. G. (1988). Annular and nonannular binding sites for cholesterol associated with the nicotinic acetylcholine receptor. Biochemistry 27, 2364-2374. doi: 10.1021/bi00407a018

Kang, J. X., and Leaf, A. (1996). Evidence that free polyunsaturated fatty acids modify $\mathrm{Na}^{+}$channels by directly binding to the channel proteins. Proc. Natl. Acad. Sci. U.S.A. 93, 3542-3546. doi: 10.1073/pnas.93.8.3542

Kang, J. X., Xiao, Y. F., and Leaf, A. (1995). Free, long-chain, polyunsaturated fatty acids reduce membrane electrical excitability in neonatal rat cardiac myocytes. Proc. Natl. Acad. Sci. U.S.A. 92, 3997-4001. doi: 10.1073/pnas.92.9.3997

Kanno, T., Shimizu, T., and Tanaka, A. (2012a). Free fatty acid derivative HUHS2002 potentiates $\alpha 7$ ACh receptor responses through indirect activation of CaMKII. Lipids 47, 865-871. doi: 10.1007/s11745-012-3701-2

Kanno, T., Tanaka, A., and Nishizaki, T. (2012b). Linoleic acid derivative DCP-LA stimulates vesicular transport of $\alpha 7 \mathrm{ACh}$ receptors towards surface membrane. Cell. Physiol. Biochem. 30, 75-82. doi: 10.1159/000339049

Kanno, T., Tsuchiya, A., Tanaka, A., and Nishizaki, T. (2013). The linoleic acid derivative DCP-LA increases membrane surface localization of the $\alpha 7 \mathrm{ACh}$ receptor in a protein $4.1 \mathrm{~N}$-dependent manner. Biochem. J. 450, 303-309. doi: 10.1042/BJ20121348

Karnovsky, M. J. (1979). Lipid domains in biological membranes: their structural and functional perturbation by free fatty acids and the regulation of receptor mobility. Co-presidential address. Am. J. Pathol. 97, 212-221.

Kim, D. (2003). Fatty acid-sensitive two-pore domain $\mathrm{K}^{+}$channels. Trends Pharmacol. Sci. 24, 648-654. doi: 10.1016/j.tips.2003.10.008

Kim, D., and Duff, R. A. (1990). Regulation of $\mathrm{K}^{+}$channels in cardiac myocytes by free fatty acids. Circulation Res. 67, 1040-1046. doi: 10.1161/01.RES.67.4.1040

Kloda, J. H., Hines, K., and Mitchell, D. C. (2007). Mechanism of free fatty acid modulation of inhibitory ligand gated ion channels. FASEB J. 21, A241.

Koenig, J. A., and Martin, I. L. (1992). Effect of free fatty acids on GABAA receptor ligand binding. Biochem. Pharmacol. 44, 11-15. doi: 10.1016/0006-2952(92)90031-D

Kuang, Q., Purhonen, P., and Hebert, H. (2015). Structure of potassium channels. Cell. Mol. Life Sci. 72, 3677-3693. doi: 10.1007/s00018-015-1948-5

Larsson, O., Deeney, J. T., Bränström, R., Berggren, P.-O., and Corkey, B. E. (1996). Activation of the ATP-sensitive $\mathrm{K}^{+}$channel by long chain Acyl-CoA. J. Biol. Chem. 271, 10623-10626. doi: 10.1074/jbc.271.18.10623

Lasalde, J. A., Colom, A., Resto, E., and Zuazaga, C. (1995). Heterogeneous distribution of acetylcholine receptors in chick myocytes induced by cholesterol enrichment. Biochim. Biophys. Acta 1235, 361-368. doi: 10.1016/0005-2736(95)80025-B

Lasalde, J. A., Tamamizu, S., Butler, D. H., Vibat, C. R., Hung, B., and McNamee, M. G. (1996). Tryptophan substitutions at the lipid-exposed transmembrane segment M4 of Torpedo californica acetylcholine receptor govern channel gating. Biochemistry 35, 14139-14148. doi: 10.1021/bi9615831

Lauritzen, I., Blondeau, N., Heurteaux, C., Widmann, C., Romey, G., and Lazdunski, M. (2000). Polyunsaturated fatty acids are potent neuroprotectors. EMBO J. 19, 1784-1793. doi: 10.1093/emboj/19.8.1784

Laus, M. N., Soccio, M., Trono, D., Liberatore, M. T., and Pastore, D. (2011). Activation of the plant mitochondrial potassium channel by free fatty acids and
acyl-CoA esters: a possible defence mechanism in the response to hyperosmotic stress. J. Exp. Botany 62, 141-154. doi: 10.1093/jxb/erq256

Lee, A. G. (2004). How lipids affect the activities of integral membrane proteins. Biochim. Biophys. Acta 1666, 62-87. doi: 10.1016/j.bbamem.2004.05.012

Lee, A. K., Smart, J. L., Rubinstein, M., Low, M. J., and Tse, A. (2011). Reciprocal regulation of TREK-1 channels by arachidonic acid and CRH in mouse corticotropes. Endocrinology 152, 1901-1910. doi: 10.1210/en.2010-1066

Lee, Y. H., Li, L., Lasalde, J., Rojas, L., McNamee, M. G., Ortiz-Miranda, S. I., et al. (1994). Mutations in the M4 domain of Torpedo californica acetylcholine receptor dramatically alter ion channel function. Biophys. J. 66, 646-653. doi: 10.1016/S0006-3495(94)80838-0

Leu, B., Koch, E., and Schmidt, J. T. (2010). GAP43 phosphorylation is critical for growth and branching of retinotectal arbors in zebrafish. Develop. Neurobiol. 70, 897-911. doi: 10.1002/dneu.20829

Li, D., Belusa, R., Nowicki, S., and Aperia, A. (2000). Arachidonic acid metabolic pathways regulating activity of renal $\mathrm{Na}^{+}-\mathrm{K}^{+}$-ATPase are age dependent. Am. J. Physiol. Renal Physiol. 278, 823-829.

Li, X., Ma, C., Zhu, D., Meng, L., Guo, L., Wang, Y., et al. (2010). Increased expression and altered subcellular distribution of PKC- $\delta$ and PKC- $\varepsilon$ in pulmonary arteries exposed to hypoxia and 15-HETE. Prostaglandins Other Lipid Mediat. 93, 84-92. doi: 10.1016/j.prostaglandins.2010.06.008

Linsdell, P. (2000). Inhibition of cystic fibrosis transmembrane conductance regulator chloride channel currents by arachidonic acid. Can. J. Physiol. Pharmacol. 78, 490-499. doi: 10.1139/y00-014

Liu, Y., Sun, Q., Chen, X., Jing, L., Wang, W., Yu, Z., et al. (2014). Linolenic acid provides multi-cellular protective effects after photothrombotic cerebral ischemia in rats. Neurochem. Res. 39, 1797-1808. doi: 10.1007/s11064-014-1390-3

López, M., Lelliott, C. J., and Vidal-Puig, A. (2007). Hypothalamic fatty acid metabolism: a housekeeping pathway that regulates food intake. Bioessays 29 , 248-261. doi: 10.1002/bies.20539

Maingret, F., Patel, A. J., Lesage, F., Lazdunski, M., and Honoré, E. (1999). Mechano- or acid stimulation, two interactive modes of activation of the TREK-1 potassium channel. J. Biol. Chem. 274, 26691-26696, doi: $10.1074 /$ jbc. 274.38 .26691

Mantipragada, S. B., Horvath, L. I., Arias, H. R., Schwarzmann, G., Sandhoff, K., Barrantes, F. J., et al. (2003). Lipid-protein interactions and effect of local anesthetics in acetylcholine receptor-rich membranes from Torpedo marmorata electric organ. Biochemistry 42, 9167-9175. doi: 10.1021/bi034485q

Marsh, D., and Barrantes, F. J. (1978). Immobilized lipid in acetylcholine receptorrich membranes from Torpedo marmorata. Proc. Natl. Acad. Sci. U.S.A. 75, 4329-4333. doi: 10.1073/pnas.75.9.4329

Meves, H. (1994). Modulation of ion channels by arachidonic acid. Prog Neurobiol. 43, 175-186. doi: 10.1016/0301-0082(94)90012-4

Minota, S., and Watanabe, S. (1997). Inhibitory effects of arachidonic acid on nicotinic transmission in bullfrog sympathetic neurons. J. Neurophysiol. 78, 2396-2401.

Mitra, A., Bailey, T. D., and Auerbach, A. L. (2004). Structural dynamics of the M4 transmembrane segment during acetylcholine receptor gating. Structure 12, 1909-1918. doi: 10.1016/j.str.2004.08.004

Moreno, C., Macías, A., Prieto, A., de la Cruz, A., González, T., and Valenzuela, C. (2012). Effects of n-3 polyunsaturated fatty acids on cardiac ion channels. Front. Physiol. 3:245. doi: 10.3389/fphys.2012.00245

Mosser, J., Douar, A. M., Sarde, C. O., Kioschis, P., Feil, R., Moser, H., et al. (1993). Putative X-linked adrenoleukodystrophy gene shares unexpected homology with ABC transporters. Nature 361, 726-730. doi: 10.1038/361726a0

Müller, M., Szewczyk, A., De Weille, J. R., and Lazdunski, M. (1992). ATP-sensitive $\mathrm{K}^{+}$channels in insulinoma cells are activated by nonesterified fatty acids. Biochemistry 19, 4656-4661. doi: 10.1021/bi00134a017

Nabekura, J., Noguchi, K., Witt, M. R., Nielsen, M., and Akaike, N. (1998). Functional modulation of human recombinant $\gamma$-aminobutyric acid type A receptor by docosahexaenoic acid. J. Biol. Chem. 273, 11056-11061. doi: 10.1074/jbc.273.18.11056

Nishizaki, T., Ikeuchi, Y., Matsuoka, T., and Sumikawa, K. (1997a). Shortterm depression and long-term enhancement of ACh-gated channel currents induced by linoleic and linolenic acid. Brain Res. 751, 253-258. doi: 10.1016/S0006-8993(96)01405-9 
Nishizaki, T., Ikeuchi, Y., Matsuoka, T., and Sumikawa, K. (1997b). Oleic acid enhances ACh receptor currents by activation of $\mathrm{Ca}^{2+} /$ calmodulin-dependent protein kinase II. Neuroreport 8, 597-601. doi: 10.1097/00001756-199702100-00004

Nishizaki, T., Matsuoka, T., Nomura, T., and Sumikawa, K. (1998). Modulation of ACh receptor currents by arachidonic acid. Mol. Brain Res. 57, 173-179. doi: 10.1016/S0169-328X(98)00091-6

Nishizaki, T., Nomura, T., Matsuoka, T., Enikolopov, G., and Sumikawa, K. (1999). Arachidonic acid induces a long-lasting facilitation of hippocampal synaptic transmission by modulating PKC activity and nicotinic ACh receptors. Mol. Brain Res. 69, 263-272. doi: 10.1016/s0169-328x(99)00117-5

Nishizaki, T., and Sumikawa, K. (1997). Lysophosphatidic acid potentiates ACh receptor currents by G-protein-mediated activation of protein kinase C. Brain Res. Mol. Brain Res. 50, 121-126. doi: 10.1016/S0169-328X(97)00177-0

Nishizuka, Y. (1995). Protein kinase C and lipid signaling for sustained cellular responses. FASEB J. 9, 484-496.

Noël, J., Sandoz, G., and Lesage, F. (2011). Molecular regulations governing TREK and TRAAK channel functions. Channels 5, 402-409. doi: 10.4161/chan.5.5.16469

Nojima, H., Sasaki, T., and Kimura, I. (2000). Arachidonic acid and prostaglandin D2 cooperatively accelerate desensitization of nicotinic acetylcholine receptor channel in mouse skeletal muscles. Brain Res. 852, 233-238. doi: 10.1016/S0006-8993(99)02206-4

Nowicki, S., Chen, S. L., Aizman, O., Cheng, X. J., Li, D., Nowicki, C., et al. (1997). 20-Hydroxyeicosa-tetraenoic acid (20 HETE) activates protein kinase C. Role in regulation of rat renal $\mathrm{Na}^{+}, \mathrm{K}^{+}$-ATPase. J. Clin. Invest. 99, 1224-1230. doi: $10.1172 /$ JCI1 19279

Nurowska, E., and Ruzzier, F. (1996). Corticosterone modifies the murine muscle acetylcholine receptor channel kinetics. Neuroreport 8, 77-80. doi: 10.1097/00001756-199612200-00016

Ohta, K., Miyamoto, H., Yaguchi, T., Nagai, K., Yamamoto, S., Nomura, T., et al. (2003). Stearic acid facilitates hippocampal neurotransmission by enhancing nicotinic ACh receptor responses via a PKC pathway. Mol. Brain Res. 119, 8389 doi: 10.1016/j.molbrainres.2003.08.017

Ordway, R. W., Singer, J. J., and Walsh, J. V. Jr. (1991). Direct regulation of ion channels by fatty acids. Trends Neurosci. 14, 96-100. doi: 10.1016/0166-2236(91)90069-7

Ortiz-Miranda, S. I., Lasalde, J. A., Pappone, P. A., and McNamee, M. G. (1997). Mutations in the M4 domain of the Torpedo californica nicotinic acetylcholine receptor alter channel opening and closing. J. Membr. Biol. 158, 17-30. doi: $10.1007 / \mathrm{s} 002329900240$

Patel, A. J., Honore, E., Maingret, F., Lesage, F., Fink, M., Duprat, F., et al. (1998). A mammalian two pore domain mechano-gated S-like $\mathrm{K}^{+}$channel. EMBO J. 17, 4283-4290. doi: 10.1093/emboj/17.15.4283

Patel, A., Lazdunski, M., and Honoré, E. (2001). Lipid and mechanogated 2P domain $\mathrm{K}^{+}$channels. Curr. Opin. Cell Biol. 13, 422-427. doi: 10.1016/S0955-0674(00)00231-3

Pérez, F. R., Casabiell, X., Camiña, J. P., Zugaza, J. L., and Casanueva, F. F. (1997). cis-unsaturated free fatty acids block growth hormone and prolactin secretion in thyrotropin-releasing hormone-stimulated $\mathrm{GH}_{3}$ cells by perturbing the function of plasma membrane integral proteins. Endocrinology 138, 264-272.

Pérez, F. R., Piñeiro, V., De La Cruz, L. F., Casanueva, F. F., and Casabiell, X. (2003). Vascular wall: potential target for the physicochemical effects of cis-unsaturated free fatty acids. Microsc. Res. Tech. 60, 23-29. doi: $10.1002 /$ jemt. 10239

Perillo, V. L., Fernández-Nievas, G. A., Vallés, A. S., Barrantes, F. J., and Antollini, S. S. (2012). The position of the double bond in monounsaturated free fatty acids is essential for the inhibition of the nicotinic acetylcholine receptor. Biochim. Biophys. Acta 1818, 2511-2520. doi: 10.1016/j.bbamem.2012.06.001

Petrou, S., Ordway, R. W., Kirber, M. T., Dopico, A. M., Hamilton, J. A., Walsh, J. V. Jr., et al. (1995). Direct effects of fatty acids and other charged lipids on ion channel activity in smooth muscle cells. Prostaglandins Leukot. Essent. Fatty Acids 52, 173-178. doi: 10.1016/0952-3278(95)90018-7

Retamar, M. A., Evangelista-Martínez, F., León-Paravic, C. G., Altenberg, G. A., and Reuss, L. (2011). Biphasic effect of linoleic acid on connexin 46 hemichannels. Pflugers Arch. 461, 635-643. doi: 10.1007/s00424-011-0936-3

Safran, A., Provenzano, C., Sagi-Eisenberg, R., and Fuchs, S. (1990). Phosphorylation of membrane-bound acetylcholine receptor by protein kinase C: characterization and subunit specificity. Biochemistry 29, 6730-6734. doi: 10.1021/bi00480a024

Samochocki, M., and Strosznajder, J. (1993). Modulatory action of arachidonic acid on GABAA/chloride channel receptor function in adult and aged brain cortex membranes. Neurochem. Int. 23, 261-267. doi: 10.1016/0197-0186(93)90117-N

Santiago, J., Guzman, G. R., Rojas, L. V., Marti, R., Asmar-Roviva, G. A., Santana, L. F., et al. (2001). Probing the effects of membrane cholesterol in the Torpedo californica acetylcholine receptor and the novel lipid-exposed mutation alpha C418W in Xenopus oocytes. J. Biol. Chem. 276, 46523-46532. doi: 10.1074/jbc.M104563200

Sarveswaran, S., Thamilselvan, V., Brodie, C., and Ghosh, J. (2011). Inhibition of 5-lipoxygenase triggers apoptosis in prostate cancer cells via downregulation of protein kinase C-epsilon. Biochim. Biophys. Acta 1813, 2108-2117. doi: 10.1016/j.bbamcr.2011.07.015

Schwartz, R. D., Skolnick, P., and Paul, S. M. (1988). Regulation of gammaaminobutyric acid/barbiturate receptor-gated chloride ion flux in brain vesicles by phospholipase A2: possible role of oxygen radicals. J. Neurochem. 50, 565-571. doi: 10.1111/j.1471-4159.1988.tb02948.x

Sekiguchi, K., Tsukuda, M., Ogita, K., Kikkawa, U., and Nishizuka, Y. (1987). Three distinct forms of rat brain protein kinase C: differential response to unsaturated fatty acids. Biochem. Biophys. Res. Commun. 145, 797-802. doi: 10.1016/0006-291X(87)91035-7

Shinomura, T., Asaoka, Y., Oka, M., Yoshida, K., and Nishizuka, Y. (1991). Synergistic action of diacylglycerol and unsaturated fatty acid for protein kinase C activation: its possible implications. Proc. Natl. Acad. Sci. U.S.A. 88, 5149-5153. doi: 10.1073/pnas.88.12.5149

Singh, T. U., Choudhury, S., Parida, S., Maruti, B. S., Kumar, S., and Mishra, S. K. (2012). Arachidonic acid inhibits $\mathrm{Na}^{+}-\mathrm{K}^{+}-$ATPase via cytochrome P-450, lipoxygenase and protein kinase C-dependent pathways in sheep pulmonary artery. Vascular Pharmacol. 56, 84-90. doi: 10.1016/j.vph.2011.11.005

Sullivan, L. C., Berg, K. A., and Clarke, W. P. (2015). Dual regulation of $\delta$-opioid receptor function by arachidonic acid metabolites in rat peripheral sensory neurons. J. Pharmacol. Exp. Ther. 353, 44-51. doi: 10.1124/jpet.114.221366

Sumida, C., Graber, R., and Nunez, E. (1993). Role of fatty acids in signal transduction: modulators and messengers. Prostaglandins Leukot. Essent. Fatty Acids 48, 117-122. doi: 10.1016/0952-3278(93)90019-S

Sun, X., Zhou, D., Zhang, P., Moczydlowski, E. G., and Haddad, G. G. (2007). $\beta$-subunit-dependent modulation of hSlo BK current by arachidonic acid. J. Neurophysiol. 97, 62-69. doi: 10.1152/jn.00700.2006

Sunshine, C., and McNamee, M. G. (1994). Lipid modulation of nicotinic acetylcholine receptor function: the role of membrane lipid composition and fluidity. Biochim. Biophys. Acta 1191, 59-64. doi: 10.1016/0005-2736(94)90233-X

Tamamizu, S., Guzman, G. R., Santiago, J., Rojas, L. V., McNamee, M. G., and Lasalde-Dominicci, J. A. (2000). Functional effects of periodic tryptophan substitutions in the alpha M4 transmembrane domain of the Torpedo californica nicotinic acetylcholine receptor. Biochemistry 39, 4666-4673. doi: $10.1021 /$ bi $992835 \mathrm{w}$

Tamamizu, S., Lee, Y., Hung, B., McNamee, M. G., and Lasalde-Dominicci, J. A. (1999). Alteration in ion channel function of mouse nicotinic acetylcholine receptor by mutations in the M4 transmembrane domain. J. Membr. Biol. 170, 157-164. doi: 10.1007/s002329900545

Tanaka, A., and Nishizaki, T. (2003). The newly synthesized linoleic acid derivative FR236924 induces a long-lasting facilitation of hippocampal neurotransmission by targeting nicotinic acetylcholine receptors. Bioorg. Med. Chem. Lett. 13, 1037-1040. doi: 10.1016/S0960-894X(03)00089-1

Tewari, K. P., Malinowska, D. H., Sherry, A. M., and Cuppoletti, J. (2000). PKA and arachidonic acid activation of human recombinant $\mathrm{ClC}-2$ chloride channels. Am. J. Physiol. Cell. Physiol. 279, C40-C50.

Vijayaraghavan, S., Huang, B., Blumenthal, E. M., and Berg, D. K. (1995). Arachidonic acid as a possible negative feedback inhibitor of nicotinic acetylcholine receptors on neurons. J. Neuroscience 15, 3679-3687.

Villar, M. T., Artigues, A., Ferragaut, J. A., and Gonzalez-Ros, J. M. (1988). Phospholipase A2 hydrolysis of membrane phospholipids causes structural alteration of the nicotinic acetylcholine receptor. Biochim. Biophys. Acta 938, 35-43. doi: 10.1016/0005-2736(88)90119-8

Villarroel, A., and Schwarz, T. L. (1996). Inhibition of the Kv4 (Shal) family of transient $\mathrm{K}^{+}$currents by arachidonic acid. J. Neurosci. 16, 2522-2531. 
Virmani, A., Pinto, L., Bauermann, O., Zerelli, S., Diedenhofen, A., Binienda, Z. K., et al. (2015). The carnitine palmitoyl transferase (CPT) system and possible relevance for neuropsychiatric and neurological conditions. Mol. Neurobiol. 52, 826-836. doi: 10.1007/s12035-015-9238-7

Wieland, S. J., Gong, Q., Poblete, H., Fletcher, J. E., Cheni, L.-Q., and Kalleni, R. G. (1996). Modulation of human muscle sodium channels by intracellular fatty acids is dependent on the channel isoform. J. Biol. Chem. 271, 19037-19041. doi: 10.1074/jbc.271.32.19037

Witt, M. R., and Nielsen, M. (1994). Characterization of the influence of unsaturated free fatty acids on brain GABA/benzodiazepine receptor binding in vitro. J. Neurochem. 62, 1432-1439. doi: 10.1046/j.1471-4159.1994.62041432.x

Witt, M. R., Poulsen, C. F., Lükensmejer, B., Westh-Hansen, S. E., Nabekura, J., Akaike, N., et al. (1999). Structural requirements for the interaction of unsaturated free fatty acids with recombinant human GABAA receptor complexes. Ann. N. Y. Acad. Sci. 30, 697-700. doi: 10.1111/j.1749-6632.1999.tb11349.x

Witt, M. R., Westh-Hansen, S. E., Baad Rasmussen, P., Hastrup, S., and Nielsen, M. (1996). Unsaturated free fatty acids increase benzodiazepine receptor agonist binding depending on the subunit composition of the GABAA receptor complex. J. Neurochem. 67, 2141-2145. doi: 10.1046/j.1471-4159.1996.67052141.x

Xiao, Y. F., Gomez, A. M., Morgan, J. P., Lederer, W. J., and Leaf, A. (1997). Suppression of voltage-gated L-type $\mathrm{Ca}^{2+}$ currents by polyunsaturated fatty acids in adult and neonatal rat ventricular myocytes. Proc. Natl. Acad. Sci. U.S.A. 94, 4182-4187. doi: 10.1073/pnas.94.8.4182

Xiao, Y. F., Kang, J. X., Morgan, J. P., and Leaf, A. (1995). Blocking effects of polyunsaturated fatty acids on $\mathrm{Na}^{+}$channels of neonatal rat ventricular myocytes. Proc. Natl. Acad. Sci. U.S.A. 92, 11000-11004. doi: $10.1073 /$ pnas.92.24.11000

Xiao, Y. F., Ke, Q., Wang, S. Y., Auktor, K., Yang, Y., Wang, G. K., et al. (2001). Single point mutations affect fatty acid block of human myocardial sodium channel alpha subunit $\mathrm{Na}^{+}$channels. Proc. Natl. Acad. Sci. U.S.A. 98, 3606-3611. doi: 10.1073/pnas.061003798

Xiao, Y. F., Wright, S. N., Wang, G. K., Morgan, J. P., and Leaf, A. (1998). Fatty acids suppress voltage-gated $\mathrm{Na}^{+}$currents in HEK293t cells transfected with the $\alpha$-subunit of the human cardiac $\mathrm{Na}^{+}$channel. Proc. Natl. Acad. Sci. U.S.A. 95, 2680-2685. doi: 10.1073/pnas.95.5.2680

Xiao, Y.-F., Wright, S. N., Wang, G. K., Morgan, J. P., and Leaf, A. (2000). Coexpression with $\beta 1$-subunit modifies the kinetics and fatty acid block of hH1 $\alpha \mathrm{Na}^{+}$channels. Am. J. Physiol. Heart Circ. Physiol. 279, H35-H46.

Xu, X. P., Erichsen, D., Börjesson, S. I., Dahlin, M., Amark, P., and Elinder, F. (2008). Polyunsaturated fatty acids and cerebrospinal fluid from children on the ketogenic diet open a voltage-gated $\mathrm{K}$ channel: a putative mechanism of antiseizure action. Epilepsy Res. 80, 57-66. doi: 10.1016/j.eplepsyres.2008.03.013

Xu, Y., Barrantes, F. J., Luo, X., Chen, K., Shen, J., and Jiang, H. (2005). Conformational dynamics of the nicotinic acetylcholine receptor channel: a 35ns molecular dynamics simulation study. J. Am. Chem. Soc. 127, 1291-1299. doi: $10.1021 / \mathrm{ja} 044577 \mathrm{i}$

Yaguchi, T., Yamamoto, S., Nagata, T., Kanno, T., Tanakab, A., and Nishizaki, T. (2005). Effects of cis-unsaturated free fatty acids on PKC- $\varepsilon$ activation and nicotinic ACh receptor responses. Mol. Brain Res. 133, 320-324. doi: 10.1016/j.molbrainres.2004.10.031

Yamamoto, S., Kanno, T., Nagata, T., Yaguchi, T., Tanaka, A., and Nishizaki, T. (2005). The linoleic acid derivative FR236924 facilitates hippocampal synaptic transmission by enhancing activity of presynaptic alpha7 acetylcholine receptors on the glutamatergic terminals. Neuroscience 130, 207-213. doi: 10.1016/j.neuroscience.2004.09.016

Yang, Z.-J., Carter, E. L., Kibler, K. K., Kwansa, H., Crafa, D. A., Martin, L. J., et al. (2012). Attenuation of neonatal ischemic brain damage using a 20-HETE synthesis inhibitor. J. Neurochem. 121, 168-179. doi: 10.1111/j.1471-4159.2012.07666.x

Yasuda, H., Kishiro, K., Izumi, N., and Nakanishi, M. (1985). Biphasic liberation of arachidonic and stearic acids during cerebral ischemia. J. Neurochem. 45 168-172. doi: 10.1111/j.1471-4159.1985.tb05489.x

Yazdi, S., Stein, M., Elinder, F., Andersson, M., and Lindahl, E. (2016). The molecular basis of polyunsaturated fatty acid interactions with the shaker voltage-gated potassium channel. PLoS Comput. Biol. 12:e1004704. doi: 10.1371/journal.pcbi.1004704

Yu, F. H., and Catterall, W. A. (2004). The VGL-chanome: a protein superfamily specialized for electrical signaling and ionic homeostasis. Sci. STKE. 253:re15. doi: 10.1126/stke.2532004re15

Zhou, J. J., and Linsdell, P. (2007). Molecular mechanism of arachidonic acid inhibition of the CFTR chloride channel. Eur. J. Pharmacol. 563, 88-91. doi: 10.1016/j.ejphar.2007.02.048

Conflict of Interest Statement: The authors declare that the research was conducted in the absence of any commercial or financial relationships that could be construed as a potential conflict of interest.

Copyright (C) 2016 Antollini and Barrantes. This is an open-access article distributed under the terms of the Creative Commons Attribution License (CC BY). The use, distribution or reproduction in other forums is permitted, provided the original author(s) or licensor are credited and that the original publication in this journal is cited, in accordance with accepted academic practice. No use, distribution or reproduction is permitted which does not comply with these terms. 